\title{
The 1979 Nice harbour catastrophe revisited: Trigger mechanism inferred from geotechnical measurements and numerical modelling
}

\author{
Gabriela DAN $^{* 1,2}$, Nabil SULTAN ${ }^{1}$, Bruno SAVOYE ${ }^{1}$
}

\author{
${ }^{1}$ IFREMER, Géosciences Marines, Laboratoire Environnements Sédimentaires, Plouzané, France \\ ${ }^{2}$ Université de Bretagne Occidentale, IUEM, CNRS UMR6538, 29280 Plouzané, France \\ *: Corresponding author : Gabriela.Dan@ifremer.fr
}

\begin{abstract}
:
In 1979, a catastrophic event occurred on the Nice continental slope (French Riviera) generating the lost of human lives and important material damages. Part of the new harbour constructed at the edge of the International Airport of Nice collapsed into the sea.

The main aim of this work was 1) to present a review of facts and details related to the 1979 accident and a review of the geological setting, and 2) to evaluate the slope stability before and after the new harbour construction, by taking into account new available data such as sediment cores and piezocone CPTU data.

The CPTU data were of great value to understand the origin of the 1979 event. They show the existence of a sensitive clay bed between 30 mbsf and 45 mbsf. Under high deviatoric load a sensitive clay layer underwent an important creep, which dramatically decreased its resistance and caused the slope failure. This working hypothesis was supported by the good agreement between the maximum thickness of the failure surface and the depth of the sensitive clay layer.

Slope stability assessment using the finite element model Femuslope show the metastable state of the Nice slope before the harbour extension. Numerical calculations demonstrated that creeping of the sensitive clay layer could be at the origin of the 1979 slide. In addition, the exceptionally heavy rainfall which occurred before the accident and consequently the seepage of fresh water probably induced the decrease of the effective stress and accelerated sediment creeping and triggered the Nice slope failure. A progressive and relatively long-term creeping failure scenario is in good agreement with the official report mentioning cracks, settlements, failures and embankment collapses occurred during land filling operations.
\end{abstract}

Keywords: Nice; 1979 event; slope stability; trigger mechanism; finite element method 


\section{1. Introduction}

Submarine slope stability analyses were often carried out for a better understanding of geological phenomena which represent a risk to the coastline areas and offshore infrastructures (Locat, 2001; Locat and Lee, 2002). Occurrences of big events involving large volumes of material were identified all over the world (e.g. Storegga slide, the Canary slide) (Masson et al., 1998; Bryn et al., 2003; Haflidason et al, 2004; Canals et al., 2004). Submarine slides can generate tsunamis and affect the coastal and offshore infrastructures. The 1755 Lisbon tsunami wave represents the largest catastrophe in Western Europe, with about 60,000 casualties (Baptista et al., 1998; Canals et al., 2004). The Great Banks event (1929) following an earthquake is also an outstanding case where an initial slope failure, occurred near the earthquake epicentre, transformed into a debris flow and generated a turbidity current that cut off submarine telegraph cables (Heezen and Ewing, 1952; Piper et al., 1985; Piper et al., 1999)

Generally, a list of triggering mechanisms can be easily assessed from an accurate knowledge of the geological setting (morphology, sediment source, earthquakes, sedimentation rates, seepage, and gas hydrates...). However, the preconditions leading to failure as well as the triggering of many of the large submarine slides throughout the world is still not well understood (Lee et al., 1991; Hampton et al., 1996; Lo cat and Lee, 2002).

In 1979, a catastrophic slope failure accompanied by a small tsunami occurred on the Nice continental slope and generated the lost of human lives and important material damages. Part of the new harbour construction collapsed into the sea during land filling operations. The aim of the present work is 1) to present a review of facts and details related to the 1979 accident and a review of the geological setting and discuss different scenario; 2) to present new available data, such as in-situ piezocone measurements (CPTU: Cone Penetration 
1 Testing) and sediment cores which provided samples for laboratory tests and 3) to evaluate

2 the stability of the Nice slope, before and after the new harbour construction.

3

4 2. Geological context

5

The Var sedimentary system is located in the Ligurian Sea (NW Mediterranean) and extends from Nice coastline (SE France) to the continental slope of Corsica (Figure 1). During the Messinian salinity cris is, characterized by $1200 \mathrm{~m}$ sea-level lowering (Savoye and Piper, 1991), the Var paleo-canyon was cut on the slope (Horn et al., 1965; Clauzon, 1978; Savoye and Piper, 1991). Following the Early Pliocene transgression, the Messinian Var Valley became a ria, where Var sediments were trapped. By the Middle Pliocene, a Gilberttype fan delta prograded to the slope break, which became the modern coastline (Clauzon et al., 1990). The Plio-Quaternary sedimentary succession deposited on the continental slope, seaward the Var delta, is $600-1000 \mathrm{~m}$ thick, and is formed by marls and conglomerates (Irr, 1984; Savoye et al., 1993). The Quaternary coastal uplift provides sediments supply from the glaciated Alps. Sediment on the upper slope is mainly supplied by the Var River, the Paillon River being a minor source of sediment. The two rivers are directly connected to canyons (Figure 1).

The continental margin offshore Nice is characterized by an absent or very narrow shelf (less than $2 \mathrm{~km}$ wide) (Figure 1). The continental slope is very steep with an average slope gradient of more than $11^{\circ}$ (Cochonat et al., 1993). The $1000 \mathrm{~m}$ isobath is reached only 5 $\mathrm{km}$ from the coastline (Savoye et al., 1989) and the slope is locally accentuated by active erosion and gully cutting.

The Var River is located in the middle of the deltaic shelf and is prolonged in the sea by the Var Canyon (Figure 2). On the right side of the Var Canyon, a flat shelf is observed close to the 1979 slide area. The shelf ranges between 0 and 15 meters depth and it is cut by 
1 several thalwegs with a SW orientation. A second shelf is observed on the south-eastern part

2 of the airport platform. The shelf is prolonged by a steep slope $\left(18-26^{\circ}\right)$, incised by many

3 submarine thalwegs.

The Var Prodelta (location on Figure 1) consists of low gradient delta-toe bottomsets, steep coarse to fine grained delta front sets affected by waves and various gravity-driven

6 processes, and topsets up to $80 \mathrm{~m}$ thick formed by a succession of muddy laminates and thin 7 peat interbeds overlaying a basal conglomerate (Dubar and Antony, 1995) (Figure 3). The 8 basal conglomerate corresponds to Würm last lowstand deposits.

\section{The 1979 Nice catastrophe} operations. On $16^{\text {th }}$ of October 1979 , a part of the airport extension, meant to be a harbour, collapse in to the sea. The harbour collapse was accompanied by a tsunami wave of 2-3 meters height (Gennesseaux et al., 1980). This catastrophic event caused the lost of human lives and important material damages. The nearby Monaco observatory did not register any earthquake that could have triggered the slide (Malinverno et al., 1988).

The submarine slide area was surveyed by EM 1000 mapping (Bourillet et al., 1992) and the slide initial volume was estimated to be about $8.7 \times 10^{6} \mathrm{~m}^{3}$ by Assier-Rzadkiewicz et al. (2000), based on the difference between the two bathymetric maps, before and after the 1979 slide. The maximum thickness of sediment is located under the corner of the new harbour construction. The average failure surface observed under the harbour construction ranges between 30 and $40 \mathrm{~m}$ water depths (Sultan et al., 2004).

The initial slide quickly transformed into a debris flow and turbidity current by progressive downslope erosion and water incorporation (Mulder et al., 1997). The path of the 1979 event is strongly marked on the upper continental slope by an incised thalweg. This 
1 thalweg is 25-40 $\mathrm{m}$ depth, $150-300 \mathrm{~m}$ wide and $4.5 \mathrm{~km}$ long (Mulder et al., 1997) and joins

2 the Var Canyon at $1000 \mathrm{~m}$ water depth (Figure 4). The flow continued its path through the

3 Var Canyon and the Middle Var Valley and cut two submarine cables $3 \mathrm{~h} 45 \mathrm{~min}$ and $8 \mathrm{~h}$ after

4 the initial failure; the cables being located at around $83-87 \mathrm{~km}$ and respectively $114 \mathrm{~km}$ from

5 the slide area (Hugot, 2000).

6

7

A sandy fresh sediment deposit, possibly linked to the 1979 event, was mapped by Piper and Savoye (1993) from high resolution seismic profiles. The volume of the sand deposit was estimated to be about $15 \times 10^{7} \mathrm{~m}^{3}$. Mulder et al. (1997), estimated the total volume of sediment deposited by the 1979 turbidity current at $15 \times 10^{8} \mathrm{~m}^{3}$, by considering that sand represents only a part of the total deposited volume.

To explain the triggering mechanism of the 1979 accident, two different scenarios were proposed. The first scenario, recommended by the MIP (MIP, 1981) suggested that the initial failure occurred on the slope and retrogressively reached the continental shelf. The initial deep failure generated the collapse of the new harbour creating the tsunami wave. On the other hand, the DDE (DDE, 1981) and Seed (Seed, 1983) proposed a different scenario: a tsunami wave was initially generated by a massive slide, around $10^{8} \mathrm{~m}^{3}$ (Seed, 1983) located at around $15 \mathrm{~km}$ from the coastline. The tsunami wave induced a lowering of the sea level at the coastline level of about $2.5 \mathrm{~m}$ (Seed, 1983). The sudden emersion of the harbour created an overload on the slope (submerged unit weight substituted by the total unit weight), sufficient to initiate static liquefaction into loose sand layer present on the continental slope and to generate the harbour collapse.

Two numerical models for tsunami and landslide have been developed (AssierRzadkiewicz et al., 2000) in order to test the validity of the two proposed scenarios. Retrogressive slide scenario (refer to M.I.P., Habib 1994) showed that the inundation observed in front of the Nice airport could be created by an initial slide of about $10.10^{6} \mathrm{~m}^{3}$. 
1 However, the wave energy would not have been sufficient to inundate the coast-line off

2 Antibes, according to witnesses' observations. The deep landslide scenario was tested for a

3 landslide with a volume of $70.10^{6} \mathrm{~m}^{3}$, located at the bottom of a canyon $3 \mathrm{~km}$ southwest off

4 Nice airport area. Such a landslide occurring approximately at the same time as the slump of

5 the building area, create amplitude and periods of the waves that match with the observation

6 but the chronology of the events is not correctly reproduced. The results of a larger and deeper

7 land slide simulation, better match with some of the whiteness's observations. The case where

8 the initial sediment mass is growing by erosion and assimilation of new material wasn't took

9 into account by Assier-Rzadkiewicz et al. (2000).

10 Slope stability assessment of the Nice area was carried out using bathymetric data 11 acquired before the 1979 event (Sultan et al., 2001). Under static conditions the area concerned by the 1979 event remains stable (Factor of Safety $>1$ ). For a sea-level lowering of $2.5 \mathrm{~m}$, the Factor of Safety decreases with respect to gravitational loading but remain s greater 14 than 1.

Several surveys were conducted after the 1979 event. The Escyanice 06 dive was 16 realized at $18 \mathrm{~km}$ from the 1979 slide on the eastern flank of the Upper Valley (location on 17 Figure 1) where an ancient bathymetric map (SHOM, France) indicated a lowering of the 18 seafloor with respect to new detailed bathymetric data (Pautot, 1981). Furthermore, it was the only area able to explain the Seed and DDE hypothesis. No evidences of fresh massive slide or erosive features were observed. However, the Seed's scenario remains the "official" truth. It is curious that the two proposed hypotheses of the 1979 event did not consider the role played by the harbour embankment loading in terms of strain generation and mechanical behav iour of the sediment from the continental shelf. 


\subsection{Ma terials}

The data used for this study (Figure 4) are obtained essentially from different IFREMER campaigns and are complemented by industrial CPTU data (Sols Essais, 1994).

The first swath bathymetric survey took place in November 1979, on the R/V Jean Charcot (Pautot, 1981). The present swath bathymetric data represents a compilation of different type of data: SeaBeam (1979), EM 1000 (1991) andd EM 300 (2000). The before 1979 DEM (Digital Elevation Model) is a compilation of pre-failure mono-beam bathymetric data for depth ranging between 0 and $150 \mathrm{~m}$ and post-failure data for the deeper part (Bourillet, 1991).

Submersible dives were conducted six months after the 1979 event, during Escyanice cruise (Escyanice, 1980), completed later by other submersible surveys (Same, 1986 and Monicya, 1989) (Figure 4).

Deep-towed side-scan sonar imagery and $3.5 \mathrm{kHz}$ profiles have been also collected during the SAME cruise in 1986 (Same, 1986) with the French S.A.R. (Système Acoustique Remorqué). The S.A.R. side-scan antenna has a mean $200 \mathrm{kHz}$ frequency and the vehicle is towed at about $100 \mathrm{~m}$ above the seafloor. The survey covers a surface of $1300 \mathrm{~km}^{2}$, but for this study, we will only use the lines collected on the upper slope (Figure 4).

Four sediment cores located on the upper slope have been recovered during two recent oceanographic surveys (GMO and Geosciences II) (Sultan et al., 2004) (Figure 4). More recently, in September 2005, the 1979 slide scarp has been sampled. Two Kullenberg cores (KENV2-01, KENV2-02) (Figure 4) were acquired in order to characterize the physical and geotechnical properties of the sediment from the failure plane. Sediment core KENV2-01 was collected just under the corner of the new harbour construction and the other one, KENV2-02, 250 meters westwards. 
2 completed the data set (Sols Essais, 1994).

\section{$3 \quad$ 4.2. Me thods}

The physical and mechanical properties of the sediment were determined with

5 different tools and tests, such as, the Multi Sensor Core Logging (http://www.geotek.co.uk)

6 (density or unit weight, compressional wave velocities, and magnetic susceptibility), the laser

7 grain-size analyser, vane shear test, water content measurements, Atterberg limits, 8 consolidation tests, etc.

9 The geomechanical properties of the sediment allow to create a lithological model of 10 the airport platform and basement. The geometry of this lithological model along dip was constrained with previous works (L'Homer, 1980; Dubar and Antony, 1995) and results from the present work. The slope geometry and lithology determination was an essential element for the assessment of the Nice slope stability and the evaluation of the Factor Of Safety $14($ FOS $)$.

The FEMUSLOPE software (Sultan et al. 2001) was used to assess the slope stability. This software is based on the finite elements method. The soil is considered as a Mohr-

17 Coulomb elastic, perfectly plastic material. The yield function $f$ is defined by the following expression:

$$
f=p \sin \varphi+q\left(\frac{\cos \theta}{\sqrt{3}} \frac{\sin \theta \sin \varphi}{3}\right)-c^{\prime} \cos \varphi^{\prime}
$$

where $c^{\prime}$ is the drained cohesion, $\varphi^{\prime}$ is the internal friction angle, $p, q$ and $\theta$ are respectively the first, second and third stress invariants. The calculation is carried out under the hypothesis of plane deformation.

In the limit equilibrium method the FOS is described as: 


$$
F O S=\frac{\text { resisting force (or moment) }}{\text { driving force (or moment) }}
$$

Using the finite element method, the determination of the FOS consists in calculating the maximum displacement for various values of FOS. The FOS is used to reduce the shear strength parameters $c^{\prime}$ or $S u$ (cohesion or undrained shear strength) and $\varphi^{\prime}$ (internal friction angle) according to the following equations to bring the slope to a limiting state or failure:

$$
c_{F O S}=\frac{c^{\prime}}{F O S}
$$

$$
\varphi_{F O S}=\tan ^{-1}\left(\frac{\varphi}{F O S}\right)
$$

$c_{F O S}$ and $\varphi_{F O S}$ are the partial shear strength parameters.

The value of FOS correspond ing to a sudden increase in displacement is considered as the critical FOS. Failure is considered to occur theoretically for a FOS equal or less than 1 . In natural environment, a FOS less than 1 is impossible, since the slope failure occurs at FOS equal to 1 . With the proposed method, the traditional definition of the $F O S$ is conserved so that the results can be directly compared with other methods. In addition to the FOS, the Finite Element Method (FEM) allows the determinations of the stress tensor, the displacement field and the yield function. Zero or positive yield function $f$ characterizes sediments undergoing

17 plastic deformation.

\section{Results}

\subsection{Morphology}

Four main thalwegs characterize the area between the Var Canyon and the Median Valley and they are shown in Fig ure 5 ( 1 to 4 from west to east). The different thalwegs are incised in their upper part and become larger (from 50-90 $\mathrm{m}$ to 200-300 m) close to their 
1 confluences with the Var Canyon. The third thalweg is directly connected to the 1979 slide

2 scar. Dotted line from Figure 5 represents the possible path of the 1979 flow down the 3 continental slope.

We present on Figure 5 an interpretation from the submersible dives: Escyanice 08 and 13 (Escyanice, 1980), Same 60 (Same, 1986) and Monicya 75 (Monicya, 1989) and from the side-scan sonar images (Same, 1986). Fresh erosion marks on the sea-floor were observed after the 1979 Nice failure based on the submersible data. Anthropogenic material and marl blocks were observed in a bend, located middle slope (black stars on Figure 5) (Monicya, 1989). These materials are certainly coming from the airport embankment. During the Monicya cruise, dive $\mathrm{n}^{\circ} 75$ (see location on Figure 4), important accumulations of marl blocs coming from the walls of the third thalweg were observed (pink circles on Figure 5). They are testifying the destabilization of the walls by turbiditic flow, possibly the 1979 flow.

At the confluence with the Var Canyon, accumulations of significant rock blocks are observed (Escyanice, 1980; Same, 1986). Limestone or conglomerate blocks are not coming from a known outcrop in the area. They correspond to blocks which were used to protect the airport embankment. We supposed that the energy of the 1979 flow was powerful enough to transport blocks of more than 1 meter diameter down to the Var Canyon.

The Var Canyon floor is covered by boulders, gravels and sand deposits (Figure 5) (Same, 1986). Lineaments pointed out at the base of the slope (Figure 5) represent the crests of gravel waves which were observed on the SAR images (Same, 1986) and during the submersible dives (Escyanice, 1980).

Evidences of massive accumulations, such as debris-flows deposits, were not observed on the thalwegs floors. It seems that, the thalwegs were by-pass zones for the 1979 event and that the 1979 flow increases its volume by erosion of the thalwegs floors and walls, continuing its path through the Var Canyon. 
The large number of small tributaries and thalwegs entrenching the Var upper slope

2 show that the 1979 event is not a so singular event in the area. The area seems to be affected

3 by important erosion processes and events like the 1979 event might have been frequent in the

4 past.

\section{$6 \quad$ 5.2. Sediment analyses}

7 5.2.1. Sedimentary description

(Figure 4). The cores description put in evidence the presence of detrital silty carbonates with some silty to fine sand quartz, few calcareous nannoplancton and occasional plant debris and gastropods (turittela) in the upper part (Sultan et al, 2004). These sedimentary facies are similar to those described by Dubar and Antony (1995). Corrected AMS radiocarbon dating a wood fragment at $3.52 \mathrm{mbsf}$, gave sedimentation rates of $11.5 \mathrm{~m} \cdot \mathrm{ky}^{-1}$ for the area located near the 1979 slide (Sultan et al., 2004). The sedimentation rates are very high but in the same range as those calculated from Dubar and Anthony (1995).

The two cores collected during the ENVAR2 cruise (KENV2-01, KENV2-02) are the first sediment samples collected on the 1979 slide scar (Figure 4). Sediment cores were collected to establish the lithology and mechanical behaviour of the sediment from the failure surface of the 1979 event.

Figure $6(\mathrm{a}, \mathrm{b})$ shows a comparison of the seafloor before the 1979 event and presentday seafloor. We estimate a maximum thickness of removed sediments, based on the two bathymetric maps (before and after 1979) of about $38 \mathrm{~m}$ for the core KENV2-01, and about $28 \mathrm{~m}$ for the other one, KENV2-02. 
$2 \mathrm{~m}$, is characterized by thin to medium sand content with values ranging between 15 and $90 \%$.

3 A layer characterized by coarse sand and 1-3 cm diameter pebbles has been observed between

$4 \quad 0.90$ and 0.97 mbsf. Below $1.75 \mathrm{~m}$ depth, the deposits are silty clay dominated (Figure 7-c).

5 Parallel- coloured (grey to red) clay laminaes characterize the lower part of the core (Figure

6 7-b). The core KENV2-01 is characterized by high unit weight with values of $19 \mathrm{kN} / \mathrm{m}^{3}$ at

7 surface, and between 20 and $22 \mathrm{kN} / \mathrm{m}^{3}$ for the rest of the core (Figure 7-d), while the

8 compression wave velocity $V p$ increases slightly with depth. The $V p$ values measured on the

9 MSCL range between $1500-1560 \mathrm{~m} / \mathrm{s}$ on the upper part and $1600-1650 \mathrm{~m} / \mathrm{s}$ in its lower part

10 (Figure 7-e). The coarse sand layer observed between 0.90 and $0.97 \mathrm{mbsf}$ is characterized by

11 a peak of about $26 \mathrm{kN} / \mathrm{m}^{3}$ and a compression wave velocity of $2400 \mathrm{~m} / \mathrm{s}$ (measured on the

12 MSCL).

The sediment core KENV2-02 is $1.38 \mathrm{~m}$ long (Figure 8-a). The grain-size distribution plot (Figure 8-c) shows an important sand content (20-90\%). Sand deposits have been described in the upper part of the core KENV2-02. The first sequence between 0.10 and 0.15 $\mathrm{m}$ depth is characterized by $5 \mathrm{~cm}$ thick coarse, yellow, non graded sand deposit. This sequence overlies almost $20 \mathrm{~cm}$ of massif coarse sand and pebbles. The pebbles can reach 6 $\mathrm{cm}$ in diameter. The sequence presents a sharp and erosive basal contact. Three non graded sand deposits alternate with coloured thin parallel clay laminaes (between 0.35 and 0.80 mbsf) (Figure 8-b). The lower part of the core is characterized by mottled facies resulting from the mixture of silty clay and discontinuous sand laminaes. The same facies was described by Sultan et al. (2004) on cores collected on the upper continental slope (MD012470, MD01-2471, KGMO-03 and KGMO-06, see figure Figure 4 for location).

The upper $10 \mathrm{~cm}$ of sediment in core KENV2-02 are characterized by a unit weight,

from $17 \mathrm{kN} / \mathrm{m}^{3}$ to $20 \mathrm{kN} / \mathrm{m}^{3}$, followed by higher unit weight values in the coarse sand and 
1 pebbles layer. Below 0.35 mbsf the unit weight range between 20 and $22 \mathrm{kN} / \mathrm{m}^{3}$ (Figure 8-d).

2 The $V p$ measurements shows values between $1500-1700 \mathrm{~m} / \mathrm{s}$, only the sand and pebbles layer

3 is reaching a maximum $V p$ of $2400 \mathrm{~m} / \mathrm{s}$ (from the MSCL) (Figure 8-e).

\subsubsection{Geotechnical parameters}

Figure 9 presents a comparison between the geotechnical properties of the cores collected on the upper slope (MD01-2470 and MD01-2471) and the two cores collected from the slide scar (KENV2-01 and KENV2-02). Figure 9 shows the undrained shear strength $(\mathrm{Su})$ measured only on clay and silty clay sediment, the sensitivity defined as the ratio between maximum undrained shear strength $(S u)$ and the remoulded undrained shear strength $\left(S u_{r e m}\right)$ and the $S u / \sigma^{\prime}{ }_{v}$ ratio where $\sigma_{v}^{\prime}$ is the vertical effective stress. The $S u$ of the ENVAR 2 cores is higher than the Geosciences II cores (Figure 9-a). For the sediment core KENV2-01, the undrained shear strength $(\mathrm{Su})$ increases linearly with depth from $5 \mathrm{kPa}$ at the seafloor level to $10 \mathrm{kPa}$ at $0.9 \mathrm{mbsf}$ (Figure 9-a). Below the sand layer (beneath $0.97 \mathrm{mbsf}$ ), the $S u$ shows a linear increase with depth, with a maximum $\mathrm{Su}$ of around $34 \mathrm{kPa}$ at $2.20 \mathrm{mbsf}$. For the sediment core KENV2-02, $S u$ of $5 \mathrm{kPa}$ was measured above the sand deposits (0.10 mbsf). Below the sand deposits, the measurements of the undrained shear strength show values of $S u$ between $9 \mathrm{kPa}$ at $0.82 \mathrm{mbsf}$ and more than $21 \mathrm{kPa}$ at $1.1 \mathrm{mbsf}$.

Figure 9-b presents the sensitivity values calculated for the four sediment cores. The high sensitivity of the sediment from the scar stands out. Sensitivity values, from the sediment cores KENV2-01 and KENV2-02, are 2 to 3 times high er than the sensitivity values measured on cores MD01-2470 and MD01-2471.

Figure 9-c presents the $S u / \sigma^{\prime}{ }_{v}$ ratio calculated for the four sediment cores. It seems that the values on the sediment core MD01-2470 and MD01-2471 are inferior to 1; only the upper sediment is characterized by values superior to 1 . The $S u / \sigma^{\prime}{ }_{v}$ ratio calculated for the 
1 two ENVAR 2 cores is higher than 1 and shows the over-consolidated nature of the sediment

2 (Fig ure 9-c).

3

$4 \quad$ 5.2.3. Consolidation geotechnical tests

Samples from cores KENV2-01 and KENV2-02 were taken at different depths in

6 order to perform 4 oedometer tests (KENV2-01 at 0.14, 0.60 and 1.37 mbsf; KENV2-02 at

$7 \quad 0.91 \mathrm{mbsf}$ ) (see white rectangles on Figure 7 and Figure 8).

Figure 10 presents the oedometer tests performed on sediment samples from KENV2-

901 and KENV2-02. Under $25 \mathrm{kPa}$ of vertical effective stress, the circulation of fresh water

within the sediment induced an important vertical collapse of the following three samples:

KENV2-01 at 0.6 and 1.37 mbsf and KENV2-02 at $0.91 \mathrm{mbsf}$ (Figure 10). The oedometer test performed on the sample acquired at 0.14 mbsf from core KENV2-01 was not affected by the fresh water circulation due to the moderate sensitivity of the sediment. The collapse of the three other samples is related to the high sensitivity of the sediment as it can be seen from

Figure 9-b. Indeed, in saturated sensitive clays, collapsive structure and sediment

16 deformation may be generated by electro-chemical changes induced by pore-water leaching

17 (Lefebvre, 1995).

Table 1 presents the results from the four consolidation tests showing the Over Consolidation Ratio $(O C R)$ calculated from the effective vertical stress and the preconsolidation effective stress $\left(O C R=\sigma_{p}^{\prime} / \sigma_{v}^{\prime}\right)$. The $O C R$ ranges from 55.6 at the top of the

21 sedimentary column to 11.21 at $1.37 \mathrm{mbsf}$ on the core KENV2-01 and it is about 21 at 0.91

22 mbsf on the core KENV2-02. The OCR values highlight the over-consolidated nature of the 23 sediment.

\section{$\underline{\text { 5.3. In-situ piezocone test }}$}


In 1994, Sols Essais carried out along the Nice coast four in-situ piezocone tests (Sols

2 Essais, 1994). One of the secondary applications of the piezocone measurement is the

3 determination of the stratigraphy and the lithology of buried sediment. Pore pressure is

4 difficult to interpret in terms of lithology. A soft clay, as well as a contractive silt, react to the

5 penetration of the rod by generating a high pore pressure. On the other hand, very stiff clay, as

6 well as very dense silty clay or a dilative silt respond in the same way in term of pore pressure

7 i.e. a low or even a negative pore pressure. However, thanks to the combination of the 3

8 classical CPT sensors measurements (tip resistance, sleeve friction and pore pressure), it is

9 possible to define a sediment classification chart (see for instance Campanella et al., 1982;

10 Robertson et al., 1986; Robertson, 1990 and Ramsey, 2002 among others). In order to define

11 the sediment type from the CPTU pz11 data, we have used in this work the diagram proposed

12 by Ramsey (2002).

In Figure 11, the corrected cone tip resistance $\left(q_{t}\right)$, the differential pore water pressure $(\Delta u)$, and the sleeve friction $(f s)$ profiles for the PZ11 test are presented (for location refer to

Figure 4). The tip resistance profile shows peaks (Figure 11-a) associated with a decrease of pore pressure (Figure 11-b), and indicating the presence of coarse-grained sediment. On the other hand, low values of the sleeve friction are observed below $30 \mathrm{mbsf}$ (Figure 11-c).

Figure 11-d shows different facies associated to the PZ 11 cone penetration profile. It is

19 interesting to point out the existence of a sensitive clay below $30 \mathrm{mbsf}$. The sensitive clay

20 layer depth, from 30 to $45 \mathrm{mbsf}$, coincides to the average depth of the failure surface. On the

21 same diagram (Figure 11-d) we can point out the presence of a very thin sand layer located at 22 around 36-37 mbsf into the sensitive clay layer. This predicted lithology matches well with the 23 lithology of cores collected in the 1979 scar.

\subsection{Geological-geotechnical model}


Geotechnical data from PZ11 site are selected to create a vertical lithological profile

2 essential for the numerical modelling. The lithological profile is divided into 14 layers and

3 each layer is characterized by different mechanical properties (see Table 2).

When sediment is sheared under an applied stress, excess pore pressure is generated that may (drained conditions) or may not (undrained conditions) dissipate depending on the

6 permeability of the sediment and the time available. The 1979 slope failure occurred after a 7 short period of the harbour construction. That is why in this work we have decided to evaluate 8 the slope stability of the Nice slope by considering the undrained mechanical parameters of the 9 clay layers (undrained shear strength) and the drained parameters for cohesionless soils (internal friction angle).

The lithology and thickness were estimated from PZ 11 lithological model (Figure 11-

d). Estimation of the undrained shear strength $(\mathrm{Su})$ for clayey layers was made based on the CPTU data according to the following equation:

$$
S u=\frac{q_{n e t}}{N k}
$$

where $q_{n e t}$ is the net cone resistance that depends on the tip resistance $q c$, the in-situ vertical effective stress, and the effective cone section ratio. $N k$ (assumed to be 12 in this case) is an empirical cone factor that depends on lithology (e.g., Lunne et al., 1997). Clay and silty clay layers are characterized by $S u$ corresponding to the average value measured for each layer during the PZ 11 CTPU test.

Shear strength of cohesionless soils, sand and silt, is usually expressed in terms of the internal friction angle $\left(\varphi^{\prime}\right)$. Numerous methods for assessing $\varphi^{\prime}$ from cone resistance have been published (Lunne et al., 1997). We used the empirical method proposed by Campanella and Robertson (1983) to determine $\varphi^{\prime}$ from the cone resistance $\left(q_{c}\right)$ and the vertical effective stress $\left(\sigma_{v}^{\prime}\right)$. Layer 12 is the last sedimentary layer characterized by geotechnical parameters identified thanks to the CPTU measurements. In the lack of any geotechnical data below layer 
1 12, two case calculations were considered: 1) layers 13 and 14 as the substratum and were

2 artificially characterized by high undrained shear strength and 2) only layer 14 was considered

3 as a substratum while the lithology of layer 13 was assumed similar to layer 11 .

\section{6. Modelling the Nice airport slope failures}

\section{$6 \quad \underline{6.1 . ~ I n p u t ~ d a t a ~}$}

In order to evaluate the slope stability before the 1979 accident, two cross-sections along $E N E-W S W$ and $N W-S E$ directions, have been selected based on the bathymetric analysis (for location see Figure 6). Comparison between the present-day seafloor surface and that before the 1979 accident on the Nice airport area, reveals a significant thickness of missing sediment (Figure 6- $\mathbf{c}$ and Figure 6-d).

For the two cross-sections, the problem domain is discretized into 4517 nodes and 1428 quadrilateral elements. Mesh and limit conditions are presented in Figure 12.

Three scenarios were considered in order to identify the triggering mechan ism responsible of the 1979 failure:

1- The first scenario considers the stability of the slope before the harbour extension.

2- The second scenario considers the load induced by the embankment of the new harbour. The unit-weight of the first layer changed, due to the embankment loading. The aim of this modelling is to quantify the impact of the new harbour construction on the sediment. We also modelled the Seed hypothesis, by considering the loading of the new harbour induced by $2.5 \mathrm{~m}$ sea level lowering.

3- The third scenario simulates the softening/creeping of the sed iment with the maximum strains generated by the harbour extension. Based on the results from the embankment 


\section{$4 \quad$ 6.2. Output data}

5 Different parameters are resulting from the numerical models and the main ones being:

6 a. The FOS which is defined from the diagram $F O S$ vs. maximum displacement on curve

7 presented in Figure 13. The critical FOS corresponds to a sudden increase in displacement.

8 b. The yield function with positive values corresponding to the plastic behaviour of the 9 sediment is also presented for the critical FOS.

c. The horizontal displacements are presented for the critical FOS.

\subsection{Results}

6.3.1. Scenario 1: Slope stability assessment before the harbour extension

To identify the origin of the 1979 slope failures and to get a reference calculation, the FOS is calculated by considering only the submerged sediment unit weight $(\gamma)$ along the two considered directions (gravity loading). For this scenario, layers 13 and 14 were considered as rigid substratum.

\section{(a) The ENE - WSW cross section}

For the ENE-WSW direction, the critical FOS is equal to 1.8 (Figure 13 a). Figure

14-1a presents the yield surface values and shows the existence of a continuous area of plastic deformation (yellow areas). Therefore, failure might occur for partial shear strength parameters corresponding to a FOS of 1.8. Curiously, and despite the stable state of the considered slope (ENE-WSW), the most critical failure surface matches well with the present location of the seafloor (orange line in Figure 14-1a). 
Figure 14-1c shows the results of the horizontal displacement calculated for a FOS

2 equal to 1.8. The maximum displacement is located along the slope and it is about $0.05 \mathrm{~m}$

3 (Fig ure 14-1c).

4 (b) The NW - SE cross section

For the NW-SE cross-section, the FOS corresponding to a sudden increase of the maximum displacement is equal to 1.45 (Figure 13-b). Figure 15-1a shows a continuous area of plastic deformation, where yield surface values are positive.

Figure 15-1b presents the horizontal displacement determined for a FOS equal to 1.45. The displacement values are higher than for the ENE - WSW direction; with a maximum horizontal displacement located in the upper part of the slope and it is about $10 \mathrm{~cm}$.

The FOS reveals to be higher than 1 before the harbour extension (1.8 and 1.45 respectively) along the two directions. The analysis however reveals the metastable state of the upper Nice slope $(F O S=1.45)$. For this reason, the origin of the sediment failures in the study area is more difficult to assess if we consider the probably large volume of sediments in a metastable state. Any external load may generate sediment failures. The same conclusion was obtained by Mulder (1992).

\subsubsection{Scenario 2: Slope stability assessment after the harbour extension}

The second scenario aims to evaluate the slope stability under the embankment loading where the harbour geometry and its additional load are considered in the calculation. The geotechnical parameters of the 14 soil layers used in this calculation test are the same as for the previous case. Only the total unit weight value of the first layer corresponding to the harbour embankment (total unit weight, $\gamma=26 \mathrm{kN} / \mathrm{m}^{3}$ ) has been added. 
(a) The ENE - WSW direction

For the first calculation, layers 13 and 14 were considered corresponding to the substratum. Figure 13-a shows the variation of the maximum displacement vs the FOS along the ENE-WSW profile. The sudden increase of the maximum displacement occurs for a FOS equal to 1.8 (Figure 13-a). The embankment did not generate any increase of the FOS (around 1.8 before and after the harbour extension) only the maximum displacement increased.

Figure 14-2a is presenting the yield function calculated for a FOS of 1.8. The plastic behaviour characterized by positive values (yellow areas) describes a continuous area from the shelf to the slope (Figure 14-2a). The base of the critical surface seems to be rooted in layer 12, which corresponds to the sensitive clay (Figure 14-2a).

Comparison between Figure 14-1a ( $1^{\text {st }}$ scenario) and Figure 14-2a $\left(2^{\text {nd }}\right.$ scenario) confirms the increase of the volume of metastable sediment, with an expansion of the critical failure surface from the slope to the shelf.

Figure 14-2b presents the horizontal displacement calculated for the present scenario $(F O S=1.8)$. We observed that the horizontal displacement expanded beneath the harbour embankment. The maximum value of the horizontal displacement is $0.055 \mathrm{~m}$. Comparison between the seafloor after the 1979 accident and the most critical failure surface obtained from the calculation confirms again that the slope failure occurred in 1979 coincides with the predicted most critical failure surface (Figure 14-2b).

An additional calculation where only layer 14 was considered as rigid has shown that the slope is characterized by a FOS between 1.7 and 1.8 and the base of the critical surface is once again initiated in layer 12 . 
(b) The NW - SE direction

Figure 13-b shows the variation of the maximum displacement vs FOS under the embankment loading conditions. The FOS values is now equal to 1.3 and shows a decrease comparing to the previous case (Figure 13-a). For this calculation, layers 13 and 14 were considered corresponding to the substratum.

Figure 15-2a show the yield function calculated for a FOS of 1.3. We observe that sediment masses characterized by plastic deformation are now activated beneath the harbour embankment and prolonged into the very sensitive clay layer. Figure 15-2b presents the horizontal displacement and shows high horizontal displacements beneath the harbour embankment (Figure 15-2b). The maximum value of the horizontal displacement is about 11 $\mathrm{cm}$.

The position of the substratum with respect to the sensitive layer seems to have a minor effect on the FOS and the position of the critical failure surface. That is why for the following scenarios only the first layer geometry where the substratum corresponds to layer 13 and layer 14 will be considered.

\section{(c) NW-SE direction under Seed's hypothesis}

According to Seed's hypothesis (Seed, 1983; Habib, 1994), a slide, with a significant initial volume, initiated $15 \mathrm{~km}$ off the coastline, induced the lowering of the sea level of about $2.5 \mathrm{~m}$, which in turn increased the load of the harbour embankment. In this section, the Seed's hypothesis is considered using the additional load resulting from a sea level lowering of 2.5 $\mathrm{m}$. Under this hypothesis, the loading mechanism consists of replacing, over the first $2.5 \mathrm{~m}$, the submerged unit weight $(\gamma)$ of the sediment (and or embankment) by the total unit weight $(\not)$ 
Figure 13-b shows that the FOS, calculated for the Seed's hypothesis, is equal to 1.25.

2 It seems that the FOS remains almost unchanged comparing with the previous case (Figure 3 13-b).

Figure 16-a presents the yield function and shows the area where the sediment is characterized by a plastic behaviour. Continuous area rooting in layer 12 is observed beneath

6 the embankment and on the slope (Figure 16-a). Comparison between Figure 16-a (Seed's 7 hypothesis) and Figure 15-2a (embankment load) shows the activation of sediment mass with 8 plastic behaviour on the slope edge under the sea level lowering.

Figure 16-b presents the horizontal displacement calculated for a FOS equal to 1.25.

Comparison between Figure 16-b and Figure 15-2b shows little increase of the horizontal displacement beneath the harbour embankment. The maximum value is now about $13 \mathrm{~cm}$ comparing to the $11 \mathrm{~cm}$ for the previous case calculation (Figure 15-b). small increase in horizontal displacement for a quasi constant FOS cannot play an important role in the 1979 slope failure.

Simulation results indicate that the harbour extension (embankment load) on the slope had the following effects on the stability of the slope:

- A decrease of the $F O S$, from 1.45 to 1.3 , for the $N W-S E$ cross section;

- An extension of the plastic area (positive yield function) beneath the harbour

The metastable state of the upper Nice slope before the harbour construction is accentuated after the new harbour construction. The Seed's hypothesis (Seed, 1983) did not imply a significant degradation of the upper Nice slope stability. However, Seed supposed that the overloading of the airport platform has generated a static liquefaction of a loose sand layer. 
1 From our in situ geotechnical measurements and coring, no such a loose sand layer was

2 identified. That is why, for our modelling we only considered the embankment emersion as a

3 consequence of the sea level lowering.

4

5 6.3.3. Scenario 3: Slope stability ass es sment under a static load and the creep of the sensitive 6 clay layer

The low FOS characterizing the $N W-S E$ cross-section and the existence of a sensitive clay have probably favoured sediment failure. Although, the FOS is greater than 1 for the two considered cross-sections, creep may induce failures in clayey slopes even for strengths lower than the peak strength (Lefebvre, 1981; Tavenas et al., 1978).

Indeed, soil creep represents strain increases with time resulting from prolonged application of a constant stress. The soil strength along a critical surface when subjected to continuous strains will degrade and the residual strength can reach the remoulded strength of the materials. Geometric changes and associated degradation of strength may then lead to slope failure if the stress state is located above a threshold given by the large deformation strength of the material (Vaunat and Leroueil, 2002).

Creep is generally divided into three stages (see Figure 17-a, after Singh and Mitchell, 1968):

- the primary creep starts at a rapid rate and slows with time. Mitchell (1964), among others, adapted the rate process theory to describe this first creep stage.

- the secondary creep has a relatively uniform rate;

- the tertiary creep has an accelerated creep rate and terminates when the material breaks or ruptures. Lefebvre (1981) proposed the concept of a "stability threshold", defined as the strength at about $8 \%$ axial strain. Lefebvre (1981) hypothesised that at 
constant deviatoric stress levels above the threshold value, failure would eventually occur due to creeping.

Several empirical models have been proposed for creep-induced failure in materials (see for instance Singh and Mitchell, 1968 and Tavenas et al., 1978). Hunter and Khalili (2000) have proposed a simple criterion, which is presented in Figure 17-b and it corresponds to:

- Creep to failure can occur at less than peak strength, with the limiting strength possibly being as low as the fully softened (or critical state) strength.

- The level of shear strain at which the onset of failure due to creep occurs is equivalent to the shear strain at peak stress $\left(\varepsilon_{\text {peak }}\right)$ in the equivalent conventional strength test.

Figure 18-a presents the deviatoric stresses $(q)$ before and after the harbour extension, along the observed failure surface of 1979 (corresponding to the present seafloor) for a FOS equal to 1. From Figure 18-a, one can observe a significant increase in deviatoric stress $(q)$ beneath and due to the harbour embankment.

Figure 18-b shows the variation of the deviatoric stress $(q)$, vs. the shear strain $\left(\varepsilon_{d}\right)$ along the 1979 failure surface. In addition to the increase of the deviatoric stress $(q)$, there is also an increase in shear strain $\left(\varepsilon_{d}\right)$. For a given $\varepsilon_{\text {peak }}$ to failure, as defined by the criterion of Hunter and Khalili (2000), Figure 18-b shows that the harbour extension decreased the creeping strain needed to initiate failure of the upper Nice slope.

\section{$\underline{\text { The NW-SEdirection }}$}

As it was expected from the $F O S$ value obtained for the $N W-S E$ cross-section and under embankment load conditions, a decrease of the undrained shear strength of about $15 \%$ (1- $\frac{1}{F O S}$ ) was needed to gen erate failure (Figure 19-a). This decrease of the undrained shear strength can be generated by the creeping of the sensitive clay layer under the embankment 
1 load. Sediment mass characterized by plastic deformation (positive yield function) is activated

2 under the harbour embankment and prolonged into the sensitive clay layer (Fig ure 19-b).

Figure 19-c presents the horizontal displacement calculated for a FOS equal to 1 . The

4 horizontal displacement is located along the slope and beneath the embankment, and the

5 maximum value is about $9 \mathrm{~cm}$ (for $F O S=1)$.

6

Table 3 summarized the main results obtained from the numerical modelling. One can point out the evolution of the FOS values and the horizontal displacement calculated for each study case. The calculation results will be discussed in the next section.

\section{Discussion}

The present study substantially improves our understanding of the triggering mechanism of the 1979 failure event. Mulder et al. (1997) considered that the Var deep-sea fan is very active and fed by 3 different types of processes: (1) hyperpycnal plumes which are directly linked to the activity of the rivers, (2) high-frequency superficial failures affecting under-consolidated sediments on upper slopes and (3) low-frequency failures affecting larger

17 volumes of sediment generated by external forcing.

\subsection{Preconditioning factors}

Several factors, related to the geological context, may influence the stability of the Var

21 Prodelta slope:

\section{- Sediment lateral variability}

Presently, the head of the submarine canyon is directly connected to the Var River mouth.

We know that ephemeral river mouth bars exists and that during huge river floods they 
1 is thus trapped into the canyon head. However, under westerly waves conditions, a substantial

2 part of the Var River plume is dispersed over the shelf in front of the airport providing fine

3 sand, silt and mud in that area (Sage, 1976).

4 Before 1969 when the Var River mouth was fixed with artificial levees, it used to migrate

5 along the coast line over distances of a few kilometres. This migration would have increased

6 through time the heterogeneity of the superficial sediment cover. The lateral variability of

7 sand layers is undocumented, although it would locally have a great impact on sediment

8 instability. Indeed, these sandy layers could represent the fresh water conduits generating the

9 increase of the sensitivity of the surrounding clay layers and therefore the formation of weak

10 layers in the area.

- Steep slopes and major erosion of the slope

The continental slope in front of the Var prodelta is steep and that considerably increases the risk of slope failure. The Var prodelta slope is undercut by numerous thalwegs. Four main thalwegs characterize the area between the Var canyon and the airport platform. These thalwegs are sharply incised in their upper part and quite large (150-200 meters) close to the confluence with the Var Canyon. The thalwegs are characterized by numerous tributaries, very narrow, some of them being initiated at middle-slope. Other thalwegs are observed eastward the continental slope off the Nice airport.

This clearly indicates that submarine failures are common features along the front of the Var delta and that this phenomenon started long before the airport construction. The undercutting creates local steep slopes that may later trigger the flank collapses.

- Hyperpycnal flows 
2 Hyperpycnal flows may form at a river mouth when the density of the fresh water with

3 substantial suspended mater is superior to the density of the ambient sea water (Bates, 1953;

4 Wright, 1977; Nemec, 1995; Mulder et al., 2003).

Mulder et al. (1997) demonstrated that hyperpycnal flows are frequent on the Var area.

6 The Var River is a relatively small river draining the south Alps. Its drainage basin contains

7 extended black shales areas that provide easily erodable particles that can be transported in

8 suspension down to the river mouth. Flash floods are frequent in spring and autumn generally

9 linked to violent storms over the Alps. Statistical analysis of the Var River discharge over the

10 last 40 years showed that the Var River can produce $24 \mathrm{~h}$ long hyperpycnal flows into the

11 canyon head every 20 years (Mulder et al., 1997). For example, the volume of sediment

12 delivered at the river mouth during the 1994 flood was about 10 times the average volume of

13 sediment delivered each year. Presently, in-situ monitoring is made along the Var Canyon in

14 order to measure the energy, the frequency and the sediment supply of the currents (ENVAR-

15 Hermes Programme). The impact of such flows on the sediment stability has not been studied 16 yet.

\subsection{Triggering mechanisms}

- Increase of the pore pressure

Two weeks before the 1979 event, intense rainfall occurred over the whole Var drainage basin and the Nice coast. This might have increase substantially the pore pressure into the sand layers below the platform and thus decreased the effective stress. However the link between the rainfall water infiltration and the pore pressure in sandy layers below the airport is not well documented but it can be inferred from the location of fresh water springs in Present Day's Nice slope. In-situ piezometer measuremens were conducted by Guglielmi 
1 (1993) on the continental slope off the Nice airport in order to quantify the location of fresh

2 water spring. Guglielmi (1993) showed that below the Nice airport the alluvial water flows

3 into the permeable sand layers intercalated within the deltaic Holocene clay deposits.

4

- Anthropogenic actions, such as the airport construction on the shelf or dams and embankment on the Var River

Land filling operations on the shelf off Nice started for the first time in 1940, in order to extend the Nice airport on the left bank of the Var River. These works implied the deviation of the Var River mouth westward. Airport expansion gained $50 \mathrm{~km}^{2}$ to sea in 1969. After 1969, the airport extended off the left bank (Sage, 1976). According to the same study, the airport extension and the urbanization has completely changed the near shore water circulation. Sage (1976) pointed out the influence, that the airport construction would have on the coastal current pattern and on the sediment distribution in the Baie des Anges. The embankment of the Var River, particularly at the river mouth, fixed the link between the river and the canyon head.

After construction of the airport, sediment delivered by the river arrived directly at the canyon head. However, in the mean time, several dams were built along the Var River valley in order to trap coarse sediments (pebbles and boulders). The impact of these dams on the sediment content and volumes delivered at the river mouth has not been accurately documented. However, we may assume that volumes of coarse material and coarseness of sediment delivery decreased dramatically because of the dams.

Numerical simulations were conducted in this study in order to point out the impact of the harbour construction on the slope stability. The first calculation carried out with the finite elements model, highlighted the metastable state of the Nice slope even before the harbour construction. The FOS was found greater than 1, but not enough to presume that the slope was 
1 safe. However, by considering the load induced by the construction of the harbour

2 embankment, the safety conditions become more critical. Moreover, the sediment mass

3 characterized by the plastic deformation (positive yield function) was activated beneath the

4 harbour embankment and an important increase of the horizontal displacement is observed

5 just below the harbour embankment. The critical surface seems to initiate in layer 12 ,

6 corresponding to the sensitive clay layer.

7 Although, the embankment generated a tiny decrease of the critical FOS, an important

8 increase of the deviatoric stress $(q)$ beneath the airport, due to the harbour embankment was

9 pointed out. In addition to this increase of the deviatoric stress $(q)$, we can clearly see an

10 increase of the shear strain $\varepsilon_{d}$. Thus, for a given $\varepsilon_{\text {peak }}$ driven to failure as defined by the

11 criterion of Hunter and Khalili (2000), we see that the harbour extension decreased the

12 creeping strain needed to cause failure of the upper Nice slope. Without the airport

13 embankment, the Nice slope would have probably failed (due to the sensitive clay layer), but

14 probably at a much later stage (without knowing the creeping rate we cannot define more

15 precisely any time period).

- Analysis of the sensitive clay layer

The geotechnical measurements (in-situ CPTU tests and laboratory consolidation tests) pointed out the presence of a sensitive clay layer. A sensitive clay is the result of slow geological processes. Most quick (sensitive) clays have been formed in sediments that were

21 deposited in sea water during the last deglaciation. The clay deposits can be leached, thereby

22 changing ion concentration in the pore water. Leaching can be caused by fresh water

23 infiltration, artesian water pressure in underlying permeable layers and by diffusion.

A sand layer was described in cores KENV2-01 and KENV2-02 within the upper sediments close to the sensitive clay layer. This sand layer represents a very permeable level, 
1 which might be a fresh water conduit into the sediment layers. It is therefore probable, that the

2 sensitive clay changed its mechanical properties by leaching due to the fresh water 3 circulation.

The 3 oedometer tests carried out on samples from KENV2-01 at 0.60 and $1.37 \mathrm{mbsf}$ and KENV2-02 at 0.91 mbsf showed the same behaviour of sediment collapse and

6 deformation under pure water circulation. This hydro-mechanical behaviour confirms the

7 presence of a high sensitive clay at the failure interface of the 1979 event.

In our model results, the critical surface seems to be initiated in layer 12 , which corresponds to the sensitive clay layer. Seafloor surface after the 1979 accident coincides with the most critical failure surface obtained from the calculation.

\subsection{Most probable scenario of slope failure}

In view of the circumstances that concurred before the Nice 1979 catastrophic event, the most probable scenario was (Figure 20):

1. The occurrence of a high permeability sand layer in the 1979 scar wall is a major preconditioning factor. This layer probably acted as a fresh water conduit, as it was observed by Guglielmi (1993), which caused an increase of the clay sensitivity (by leaching) and a decrease of the effective stress (Figure 20-a).

2. Taking into account the load induced by the harbour construction, the embankment probably generated softening of the mechanical properties of the sensitive clay layer and an increase in creeping (Figure 20-b).

3. Possible increase of the pore pressure after a period of rainfall could also play an important role. Pore pressures would induce a decrease of the effective stress and conduct to failure (Figure 20-c). 
1 Those three factors were enough to trigger the initial slide that secondly evolved into a

2 turbiditic current which probably cut a sharp thalweg in to the Var upper slope, incorporating a

3 large volume of new material along its path down the Var Canyon.

\subsection{Prediction of potential future slope failures}

For what we know now, there is no doubt, the airport platform area is clearly metastable and several triggering mechanisms are still active. To go ahead and better predict what could happen in the future under different loading conditions, we obviously need to have a better knowledge of the sensitive clay spatial and vertical pattern and of the distribution of sandy layers all over the slope, and particularly below the airport. We believe that the occurrence of this sen sitive clay is a highly important observation. Does this layer cover the whole area under the airport platform? Does it become sensitive only within the pathways linked to the proximity of narrow sandy channels? We cannot answer these questions using today available data; however, these are certainly crucial questions for assessing the present stability state of the airport platform.

We also need to get a better knowledge of the spatial and temporal pore pressure variations in some sandy layers that might be fed by the Var River discharge and rainfall water. A monitoring of microtopography evolutions offshore the airport platform might also help tracking the precursory signs of slope instability.

Since the 1979 event was not triggered by an earthquake, we did not take in to account earthquakes as possible triggering mechanism. However, this area may be affected by moderate earthquakes (Magnitude up to 7). Under cyclic loading, the sediments dynamic behaviour is controlled by the sediment characteristics (grain-size distribution, presence or absence of a clay fraction, etc...), and by the intensity and duration of the cyclic loading 
1 liquefaction. The depositional pattern of sand and silt in the first hundred meters of

2 sedimentary column is not documented at an accurate scale today.

Acquisition of high resolution (sparker) and very high resolution (chirp mud penetrator) seismic lines across the Var delta platform and upper slope would also be necessary to be able to make assumptions regarding the stability of the upper slope under earthquake load ing.

\section{Conclusion}

In 1979, a catastrophic event occurred on the Nice continental slope (French Riviera) generating the lost of human lives and important material damages. Part of the new harbour that was in construction at the edge of the International Airport of Nice has collapsed into the sea. The aim of this paper is to describe the 1979 event and to re-evaluate the slope stability of the near Nice harbour area.

The main results of this study are:

1. New sediment cores coming from the 1979 slide scar were used to determine the mechanical properties of the sediments left behind the 1979 slide. We put in evidence the presence of a layer (KENV2-01 and KENV2-02, see figure 7) having a sen sitivity 2 to 3 times higher than the surrounding sediment (MD01-2470 and MD01-2471, see figure 7).

2. The first calculation using the finite element model, highlights the metastable state of the Nice slope even before the harbour construction took place. The FOS is greater than 1 , but not enough to presume that the slope is safe.

3. After embankment loading, a sediment mass characterized by plastic deformation (positive yield function) is activated under the harbour embankment and prolonged into the very sensitive clay layer (layer 12). Furthermore, an important increase of the 
horizontal displacement takes place under the harbour embankment. The critical surface seems to initiate in layer 12 , which corresponds to the sensitive clay layer. The seafloor after the 1979 accident coincides with the most critical failure surface predicted from the numerical calculations.

4. Failure of the Nice slope may take place for a decrease of only $15 \%$ of the undrained shear strength $(\mathrm{Su})$ due to softening of the sensitive clay layer.

5. Our modelling results, showing a relatively long-term failure (by creep), are in good agreement with the official report mentioning that during the landfill operations, 110 reports of cracks, settlements, failures and embankment collapse occurred.

6. The 1979 Nice harbour accident was probably initiated by the combination of several factors: the load of the harbour embankment, the circulation of fresh water in the permeable sand layer and the creeping of the sensitive clay layer.

\section{Acknowledgements}

This work has been developed within the EURODOM European Project (contract RTN2-2001-00281). Financial supports were provided by IFREMER and the "Agence

Nationale de Recherche“(ISIS). The support by officers and crew during Géosciences II, and ENVAR2 cruises is greatly appreciated. The authors acknowledge Jérôme Blandin, chief scientist of the ENVAR2 cruise, Bernard Dennielou, Antonio Cattaneo and Jacques Déverchère for their useful suggestions and remarks. Constructive comments by Roger Urgeles, an Anonymous reviewer and the Editor helped significantly to improve the manuscript. 
2

3

\section{References}

Assier-Rzadkiewicz, S., Heinrich, P., Sabatier, P.C., Savoye, B., Bourillet, J.F., 2000. Numerical modelling of a landslide-generated tsunami: the 1979 Nice event. Pure Applied Geophysics 157, 1707-1727.

Baptista, M. A., Miranda, P.M.A., Miranda, J.M., Mendes Victor, L., 1998. Constrains on the source of the 1755 Lisbon tsunami inferred from numerical modelling of historical data. J. Geodyn. 25, 159-174.

Bates, C. C., 1953. Rational theory of delta formation. American Association of Petroleum Geologists Bulletin 37, 2119-2162.

Bourillet, J. F., 1991. Géomorphologie à partir d'un modèle numérique de terrain (Baie des Anges, Nice). 3rd Cong. Fr. Sedimentology; Brest.

Bourillet, J. F., Edy, C., Normand, A., 1992. Nouvel ensemble pour la reconnaissance du plateau continental: Sondeur multifaisceaux EM1000 et logiciel Trimus. Un exemple: la Baie des Anges (France). CIESM Rapp. int. Mer Médit.33, 112.

Bryn, P., Solheim, A., Berg, K., Lien, R., Forsberg, K.F., Haflidason, C.F., Ottesen, D., Rise, L., 2003. The Storegga Slide Complex: repeated large scale sliding in response to clymatic cyclicity. In: Locat, J., Mienert, J. (Eds.), Submarine Mass Movements and Their Consequences. Kluwer Acad. Publ., Dordrecth, The Neterlands, pp. 215-222. 
1 Campanella, R. G., Gillespie, D., Robertson, P.K., 1982. Pore pressures during cone penetration testing. Proceedings of the 2nd European Symposium on Penetration Testing, ESOPT-2, Amsterdam 2, pp: 507-512.

Campanella, R. G., Robertson, P.K., 1983. Interpretation of cone penetration tests: Part II: Clays. Can. Geotech. Journ. 20, 734-745.

Canals, M., Lastras, G., Urgeles, R., Casamor, J.L., Mienert, J., Cattaneo, A., De Battist, M., Haflidason, H., Imbo, Y., Laberg, J.S., Locat, J., Long, D., Longva, O., Masson, DG., Sultan, N., Trincardi, F., Bryn, P., 2004. Slope failure dynamics and impacts from seafloor and shallow sub-seafloor geophysical data: case studies from the COSTA project. Marine Geology 213, 9-72.

Clauzon, G., 1978. The Messinian Var Canyon (Provence, southern France)-paleogepgraphic implications. Marine Geology 27, 231-246.

Clauzon, G., Suc, J.P., Aguilar, J.P., Ambert, P., cappetta, H., Cravatte, J., Michaux, J., Roiron, P., Rubino, J.L., Savoye, B., Vernet, J.L., 1990. Pliocene Geodynamic and Climatic Evolutions in the French Mediterranean Region. Paleontologia di Evolucio

Cochonat, P., Bourillet, J.F., Savoye, B., Dodd, L., 1993. Geotechnical characteristics and instability of submarine slope sediments, the Nice slope (N-W Mediterranean Sea). Marine Georessources and Geotechnology 11, 131-151. 
1 DDE, 1981. Rapport de la Direction Departementale de l'Equipement des Alpes-Maritimes

4 Dubar, M., Antony, E.J., 1995. Holocene Environmental Change and River-Mouth

7 Escyanice (1980). Escyan ice Cruise Report, IFREMER

8

9 Gennesseaux, M., Mauffret, A., Pautot, G., 1980. Les glissements sous-marins de la pente

Guglielmi, Y., 1993. Gydrogéologie des aquifères Plio-Quaternaires de la Basse Vallée du Var. Thèse d'Etat, Académie d'Aix-Marseille, pp. 170.

Habib, P., 1994. Aspects géotechniques de l'accident du nouveau port de Nice. Revue Française de Géotechnique 65, 3-15.

Haflidason, H., Sejrup, H.P., Nygard, A., Bryn, P., Lien, R., Berg, K., Masson, D.G., Forberg, C.F., 2004. Architecture, geometry and slide development of the the Storegga Slide. Marine Geology 213, 201-234.

Hampton, M. A., Lee, H.J., Locat, J., 1996. Submarine landslides. Reviews of Geophysics 34, 33-59. 
1 Heezen, B. C., Ewing, M., 1952. Turbidity currents and submarine slumps, and the 1929 Grand Banks earthquake. Am. J. Sci. 250, 849-873.

3

4 Horn, R., Menard, F., Munch, F., 1965. Etude géophysique de la basse vallée du Var. Rapp. DS 65 A37, BRGM Orléans.

6

7 Hugot, A., 2000. Modélisation des écoulements gravitaires catastrophiques par une approche objet dynamique: érosion-transport-dépôt. Thèse, Université Paris 6, pp. 410.

10 Hunter, G., Khalili, N., 2000. A simple criterion for creep induced failure of overconsolidated clays. Pro. GeoEng. 2000 Conference.

Irr, F., 1984. Paléoenvironnements et évolution géodynamique néogènes et quaternaires de la bordure nord du bassin méd itérranéen occiden tal." Thèse d'Etat, Nice, $464 \mathrm{p}$.

L'Homer, A., 1980. Etude sédimentologique des carottes des sondages (Nouveau port de Nice). Rapp. ES (10) 03.80, BRGM Orléans.

Lee, H. J., Schwab, W.C., Edwards, B.D., Kayen, R.E., 1991. Quantitative controls on submarine slope failure morphology. Marine Geotechnology 10, 143-157.

Lefebvre, G., 1981. Strength and slope stability in Canadian soft clay deposits. Canadian Geotechnical Journal 18, 420-442. 
1 and saturated soils. In: E.Derbyshire et al. (Eds.), Genesis and properties of collapsible 2 soils, Kluver Academic Publishers, pp. 361-374.

3

4 Locat, J., 2001. Instabilities along ocean margins: a geomophological and geotechnical 5 perspective. Marine and Petroleum Geology 18, 503-512.

6

7 Locat, J., Lee, H.J., 2002. Submarine landslides: advances and challenges. Can. Geotech. Journ. 39, 193-212.

9

Lunne, T., Robertson, P.K., Powell, J.J.M., 1997. Cone Penetration Test in Geotechnical Practice, Blackie Academic and Professional, UK, 312 pp.

Maliverno, A., Ryan, W.B.F., Auffret, G., Pautot, G., 1988. Sonar images of the path of recent failure events on the continental margin off Nice, France. Geol. Soc. Am. Spec. Pap 229, 59-75.

Masson, D. G., Canals, M., Alonso, B., Urgeles, R., Huhnerbach, C., 1998. The Canary Debris Flow: source area morphology and failure mechanism. Sedimentology 45, 411432.

MIP, 1981. Mission d'Inspection Pluridisciplinaire sur le sinistre de Nice du 16 Octobre 1979, Rapport final. Unpublished report.

24 Mitchell, J. K., 1964. Shearing resistance of soils as a rate process. Journal of the Soil Mechanics and Foundations Division, ASCE, 90, 29-61. 
2 Monicya, 1989. Monicya Cruise Report, IFREMER

3

4 Mulder, T., 1992. Aspects géotechniques de la stabilité des marges continentales. Application à la Baie des Anges, Nice, France. Thèse, Institut National Polytechnique de Lorraine. $193 \mathrm{pp}$

7

8 Mulder, T., Savoye, B., Syvitski; J.P.M., 1997. Numerical modelling of a mid-sized gravity flow: the 1979 Nice turbidity current (dynamics, processes, sediment budget and seafloor

Mulder, T., Syvitski, J.P.M., Migeon, S., Faugères J.-C., Savoye, B., 2003. Marine hyperpycnal flows: initiation, behaviour and related deposits. A review. Marine and Petroleum Geology 20, 861-882.

Nemec, W., 1995. The dynamics of deltaic suspension plumes. In: Oti, M.N., G Postma (Eds.) Geology of Deltas, pp. 31-93.

Pautot, G., 1981. Carte morphologique de la Baie des Anges, Modèle d'instabilité de pente continentale. Oceanologica Acta 4, 203-212.

Piper, D. J. W., Shor, A.N., Farre, J.A., O'Connell, S., Jacobi, R., 1985. Sediment slides around the epicentre of the 1929 Great Banks earthquake. Geology 13, 538-541.

Piper, D. J. W., Savoye, B., 1993. Processes of late Quaternary turbidity current flow and 
deposition on the Var deep-sea fan, north-west Mediterranean Sea. Sedimentology 40, 557-582.

3

4 Piper, D. J. W., Cochonat, P., Morrison, M.L., 1999. The sequence of events around the epicentre of the 1929 Great Banks earthquake: initiation of debris flow and turbidity current inferred from sidescan sonar. Sedimentology 46, 79-97.

Ramsey, N., 2002. A calibrated model for the interpretation of cone penetration tests (CPTs) in North Sea quaternary soils. Proc. Offshore Site Investigation and Geotechnics: diversity and Sustainability, London, UK, pp. 341-356.

Robertson, P. K., Campanella, R.G., Gillespie D., Grieg, J., 1986. Use of Piezometer cone data, Proceedings, Use of In-situ Tests in Geotechnical Engineering (In-situ '86). GSP, American Society of Civil Engineers, New York 6.

Robertson, P. K., 1990. Soil classification using the cone penetration test. Can. Geotech. Journ. 27, 151-158.

Sage, L., 1976. La sédimentation à l'embouchure d'un fleuve côtier méditerranéen. Le Var. Thèse, Université de Nice, 243 pp. 
Meeting of Sedimentlogy, Budapest (1989).

2

3 Savoye, B., Piper, D.J.W., 1991. The Messinian event on the margin of the Mediterranean Sea in the Nice area, southern France. Marine Geology 97, 279-304.

6 Savoye, B., Piper, D.J.W., Droz, L., 1993. Plio-Pleistocene evolution of the Var deep-sea fan off the French Riviera. Marine and Petroleum Geology 10, 550-571.

Seed, B. H., 1983. Recheche de la cause du glissement du Port de Nice, survenu le $16: 10: 79$. Unpublished report.

Singh, A., Mitchell, J.K., 1968. General stress strain time function for soils. J. Soil Mech. Found. Eng. Div. ASCE, SM1, pp 21-43.

Sols Essais, 1994. Sols Essais Internal Report.

Sultan, N., Cochonat, P., Bourillet, J.F., Cayocca, F., 2001. Evaluation of the Risk of Marine Slope Instability: A Pseudo-3D Approach for Application to Large Areas. Marine Georessources and Geotechnology 19, 107-133.

Sultan, N., Cochonat, P., Canals, M., Cattaneo, A., Dennielou, B., Haflidason, H., Laberg, J.S., Long, D., Mienert, J., Trincardi F., Urgeles, R.,, Vorrene, T.O., Wilson, C., 2004. Triggering mechanisms of slope instability processes and sediment failures on continental margins: a geotechnical approach. Marine Geology 213, 291- 321. 
1 Tavenas, F., Leroueil, S., La Rochelle, P., Roy, M. (1978). Creep behaviour of an undisturbed 2 lightly overconsolidated clay. Canadian Geotechnical Journal 15, 402-423.

3

4 Vaunat, J., Leroueil, S., 2002. Analysis of Post-Failure Slope Movements within the 5 Framework of Hazard and Risk Analysis. Natural Hazards 26, 83-109.

6

7 Wright, L. D., 1977. Sediment transport and deposition at river mouths; a synthesis. Geological Society of America Bulletin, 88, 857-868. 
Table captions:

2

3 Table 1: Geotechnical parameters used for the finite element calculation

4 Table 2: Results from the consolidation tests

5 Table 3: Summary of the results obtained from the numerical modelling

6

7 Figure captions:

8

9 Figure 1: General bathymetric map of the Ligurian Sea and the Var sedimentary system showing its main features (Mercator, WGS 1984)

11

Figure 2: Bathymetric map showing a zoom on the continental shelf and the 1979 slide area

(Mercator, WGS 1984).

Figure 3: Schematic cross section of the Var Holocene delta, from Dubar and Anthony (1995).

Figure 4: Bathymetric map showing the available data: side scan sonar data (Same, 1986) and submersible dives: Escyanice 08 et 13 (Escyanice, 1980); Same 60 (Same, 1986) and

Figure 5: Interpretation of the submersible observation and side scan sonar data. Fresh erosion marks and blocks accumulations are observed on the 1979 flow path (red lines) 25

Figure 6: (a) Contour maps before 1979 accident and (b) after the 1979 accident showing the change on the slope morphology and the ENVAR2 cores location: (c) ENE-WSW crosssection showing the seafloor surface before and after the 1979 event and KENV2-02 


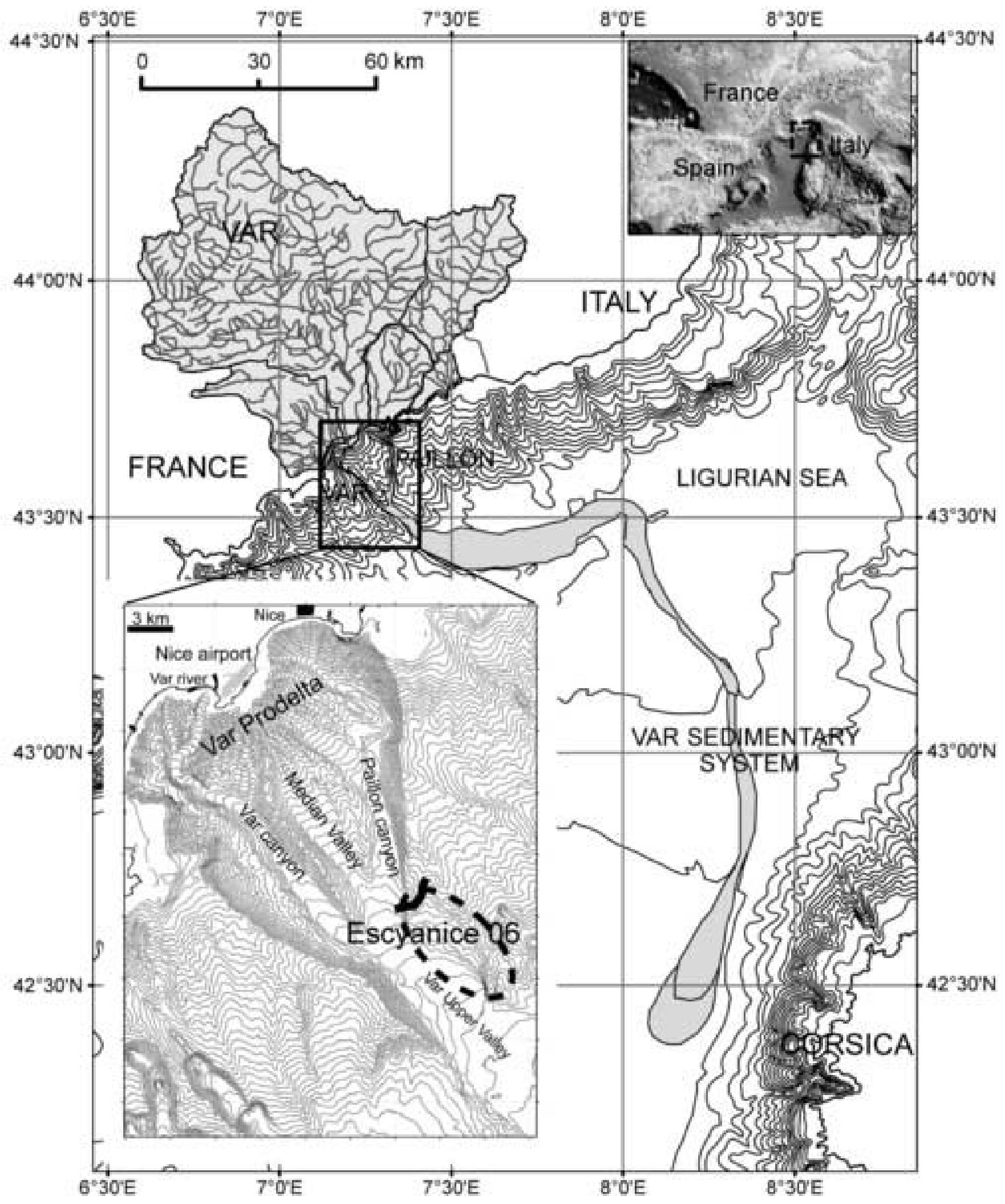


igure 2

lick here to download high resolution image

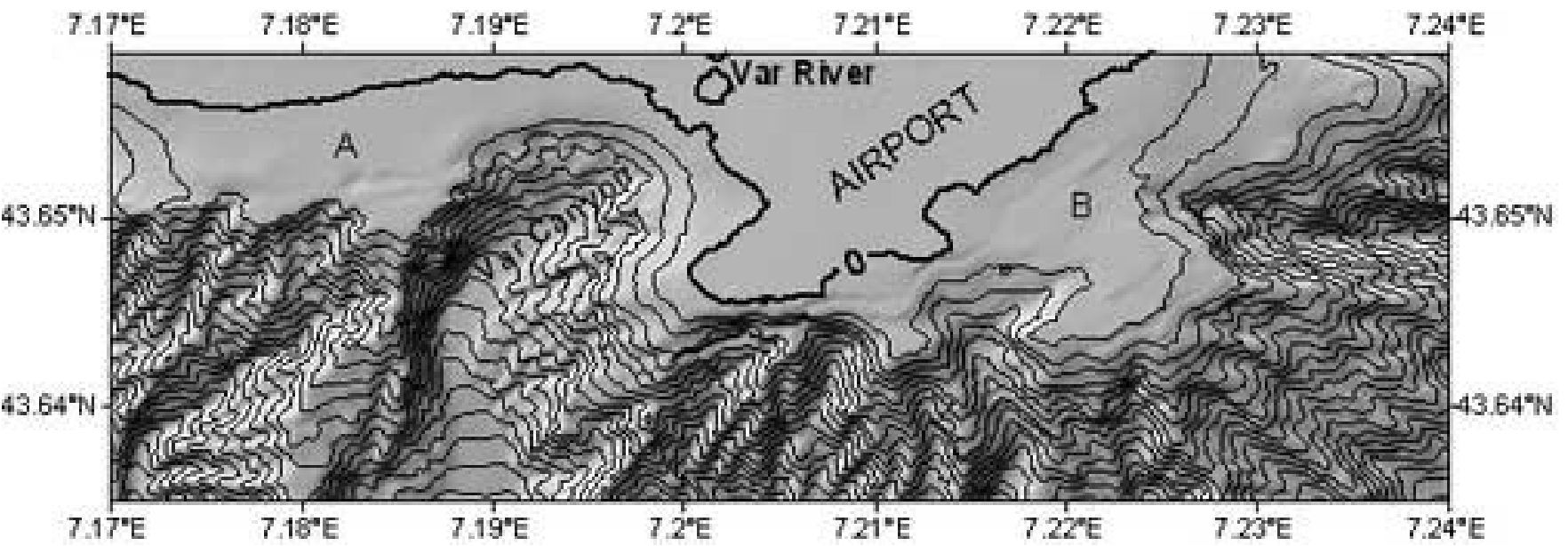


igure 3

-lick here to download high resolution image

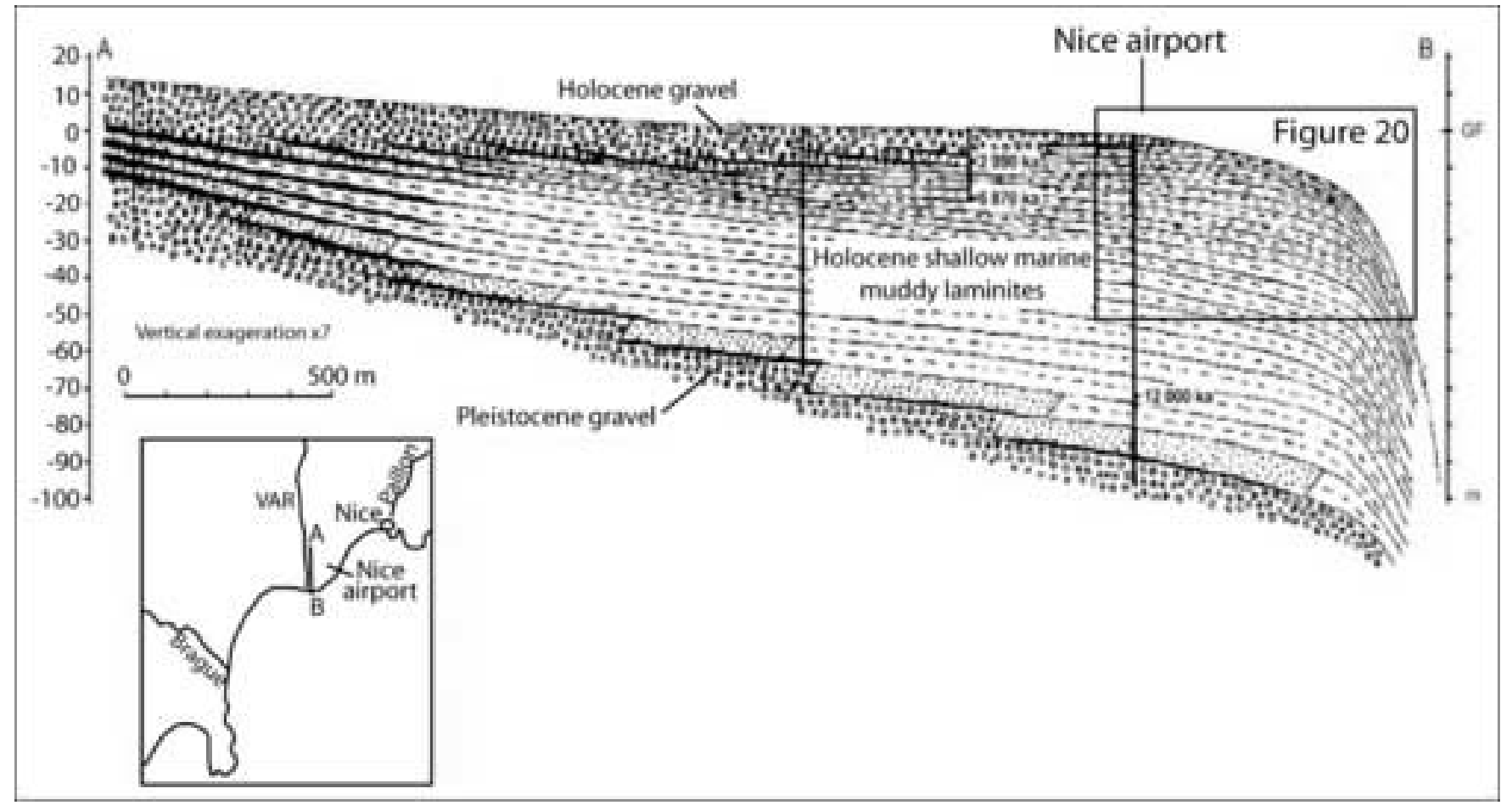




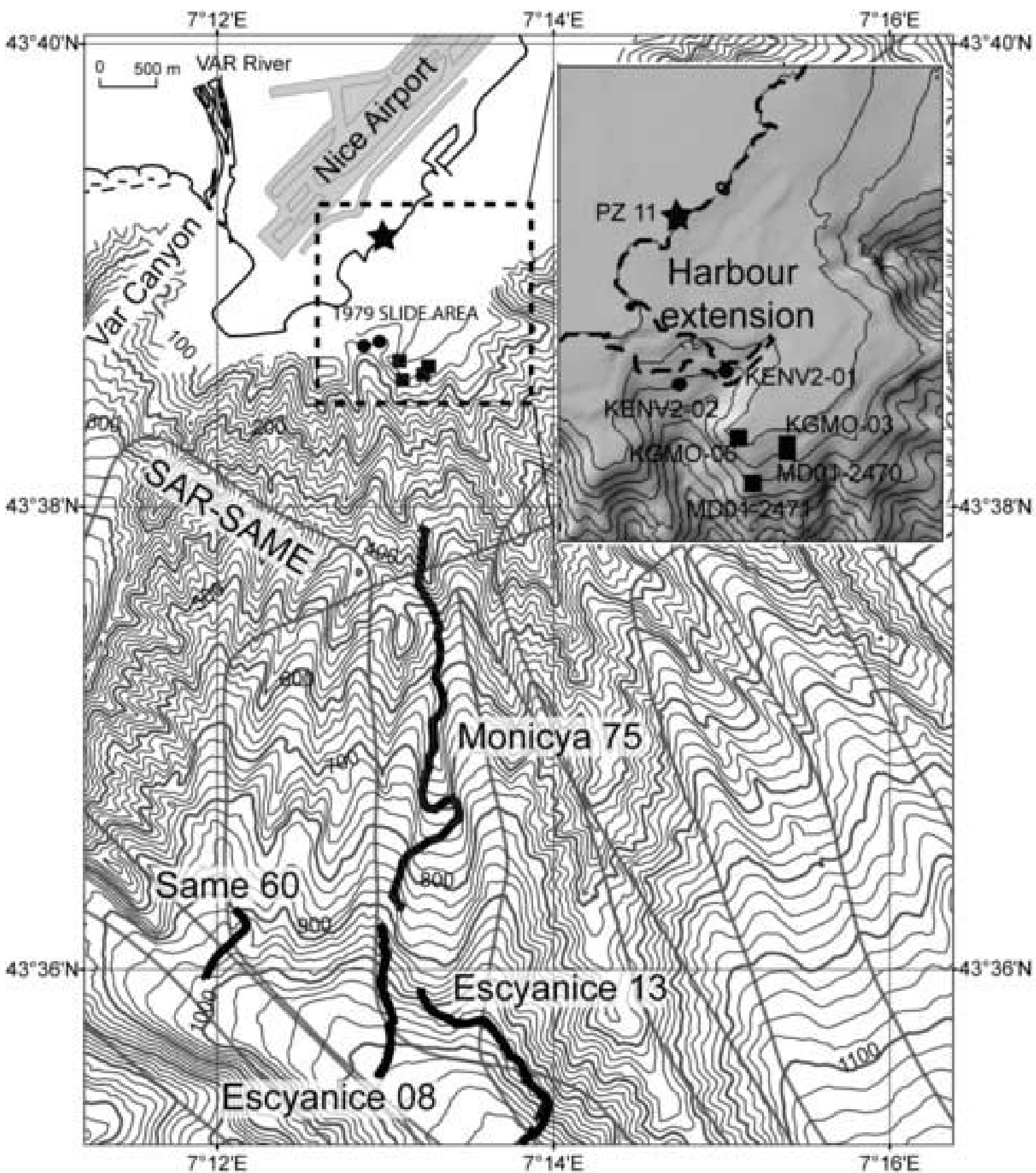




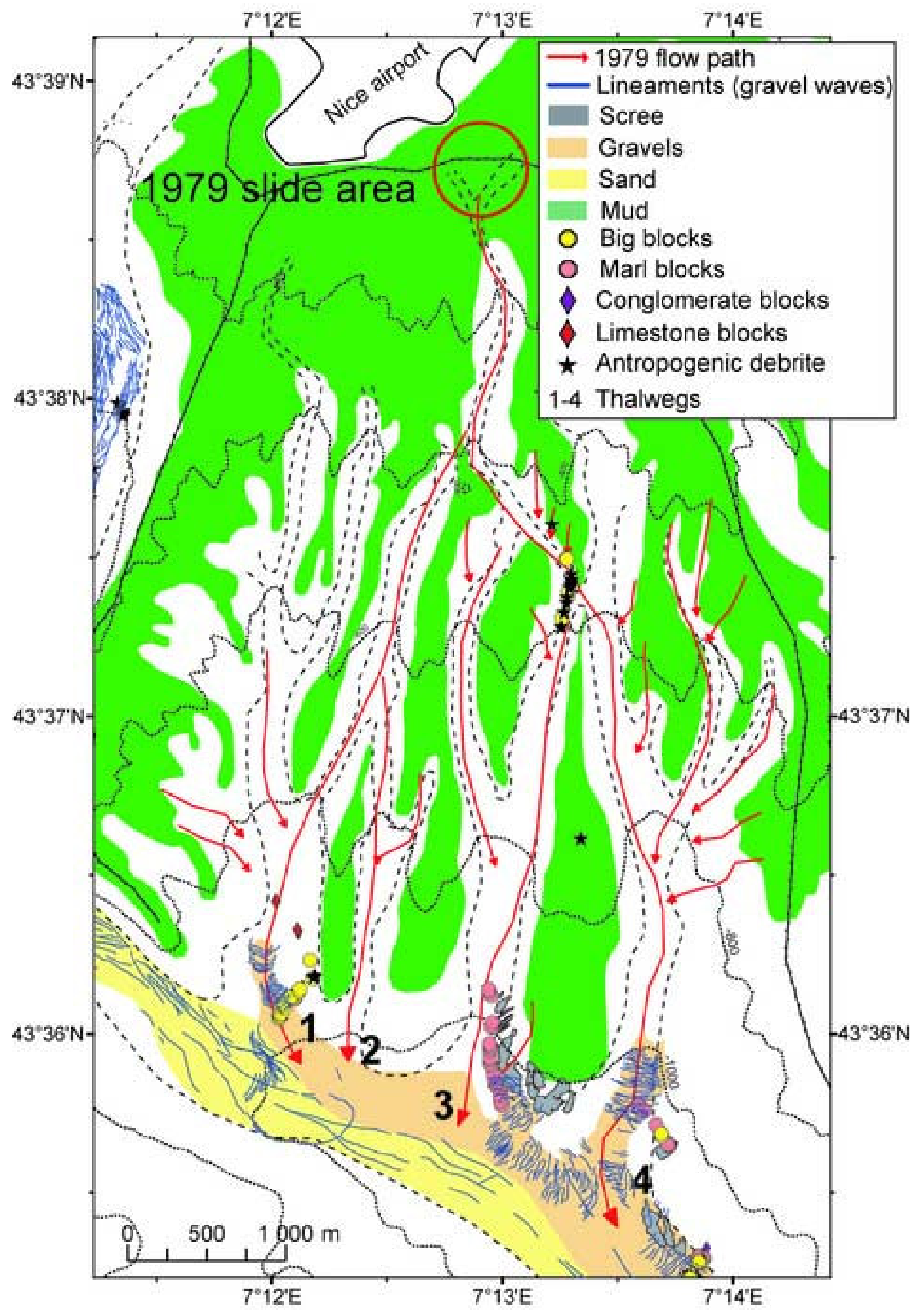


(a)

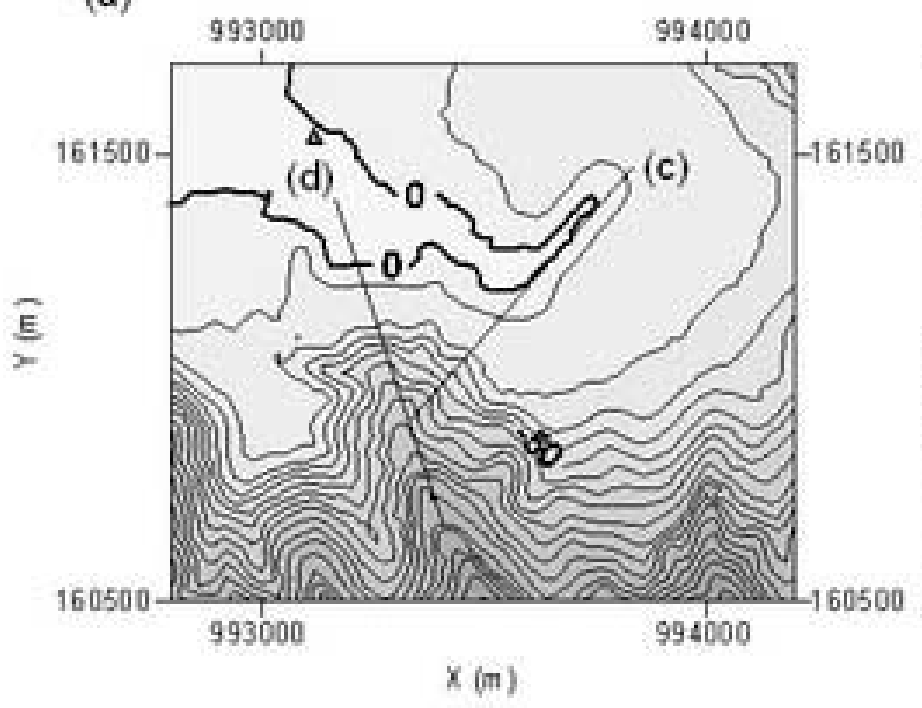

(b)

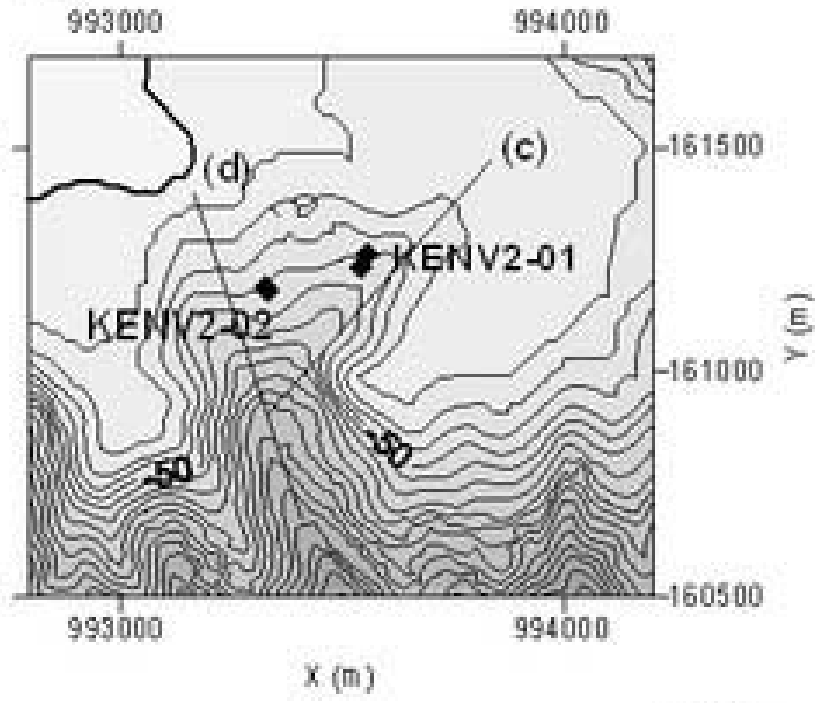

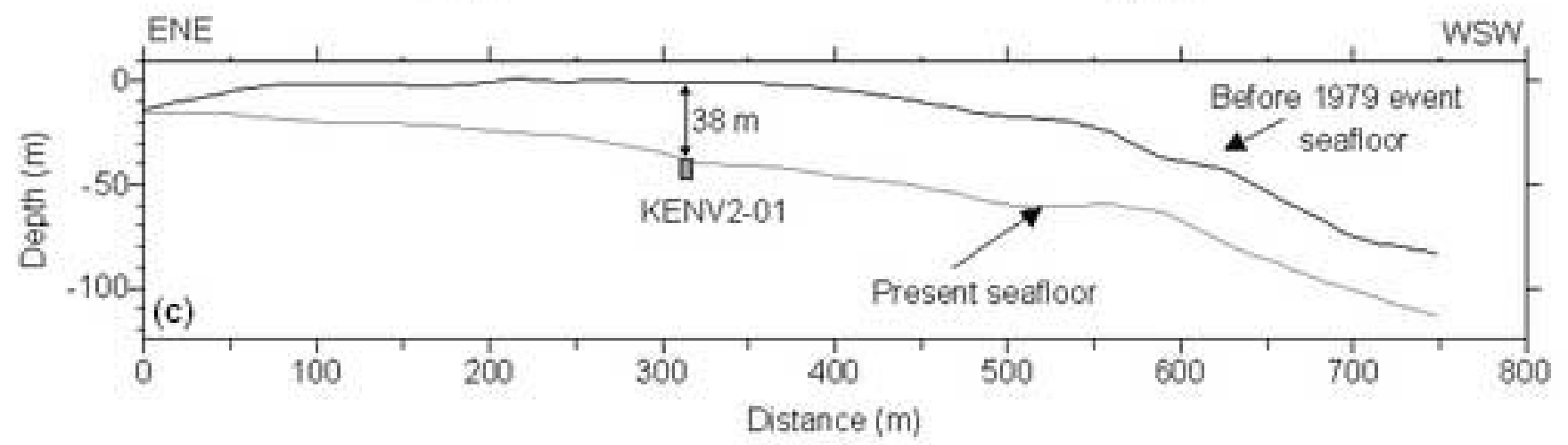

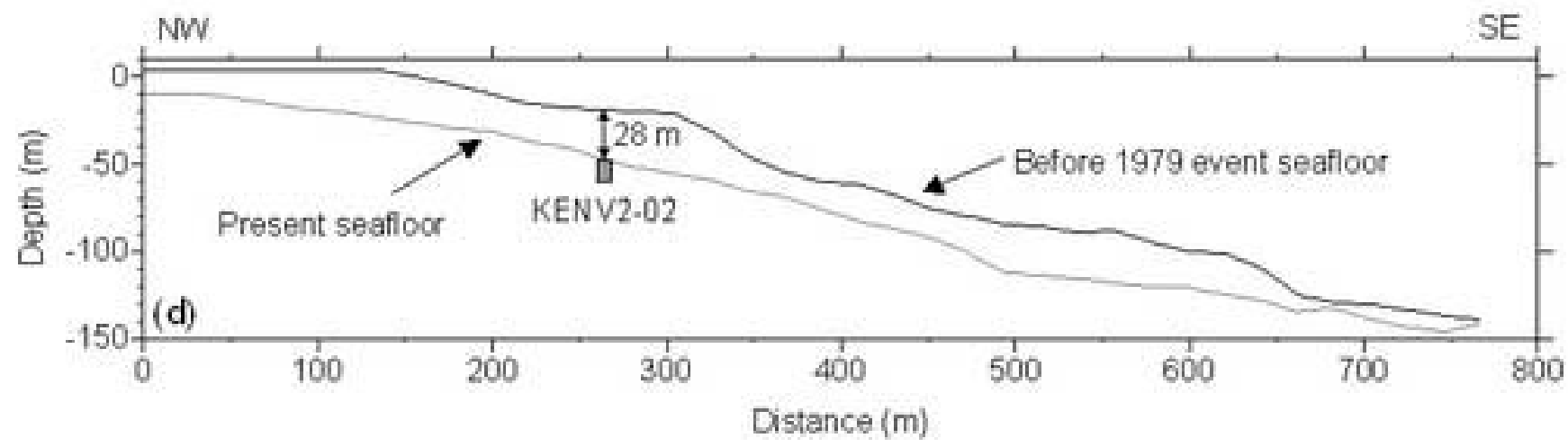




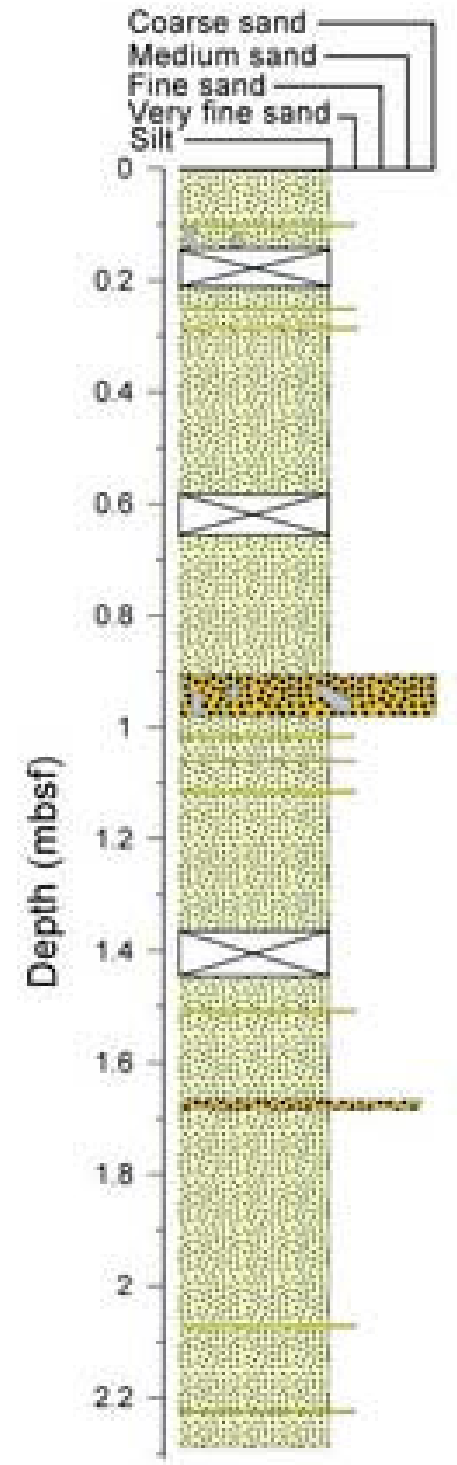

(a)

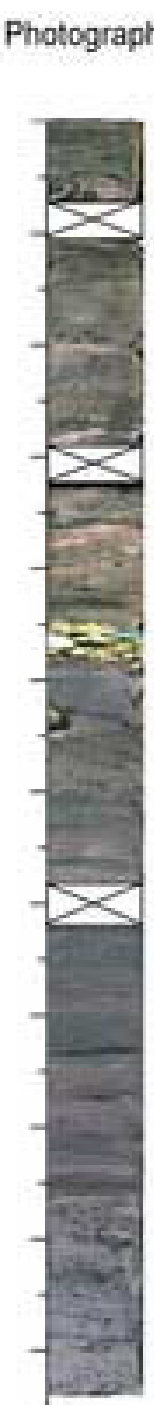

(b)

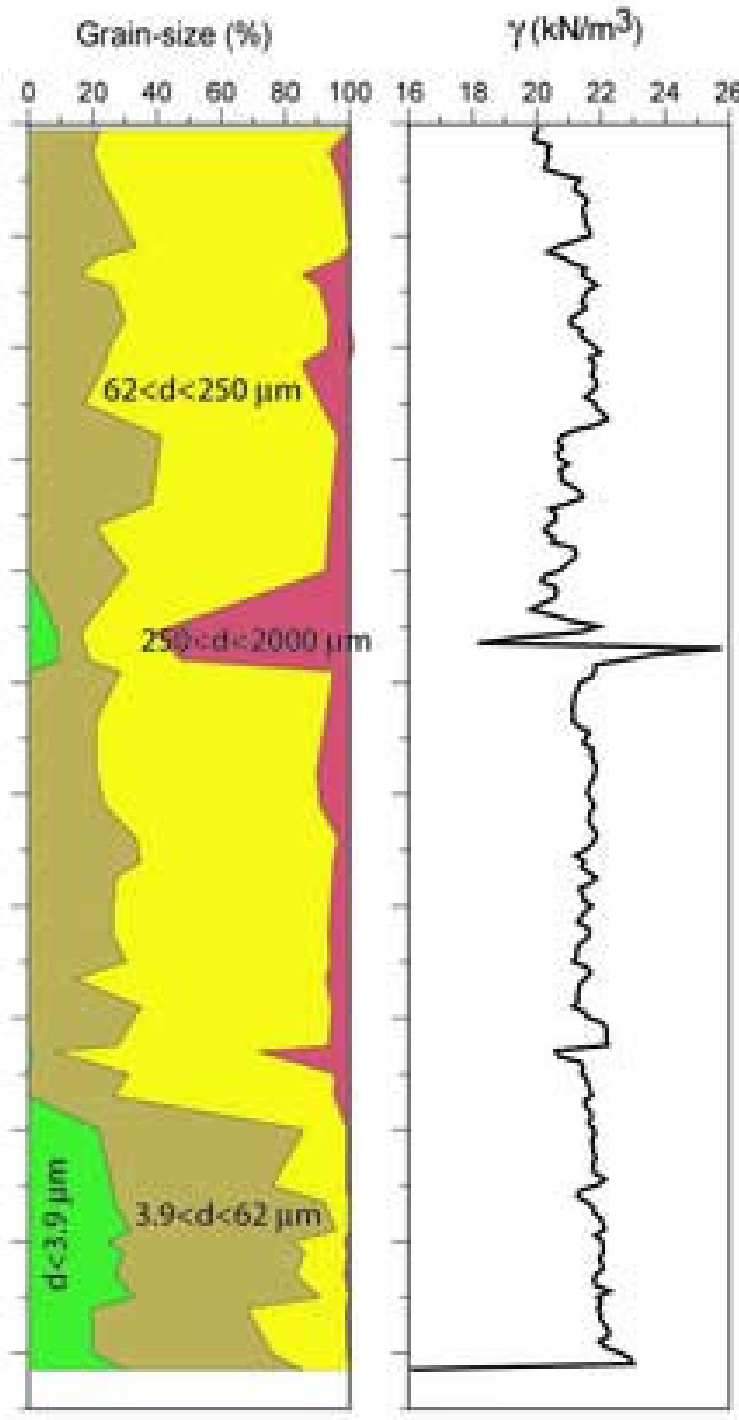

(d)
$V p(m / s)$

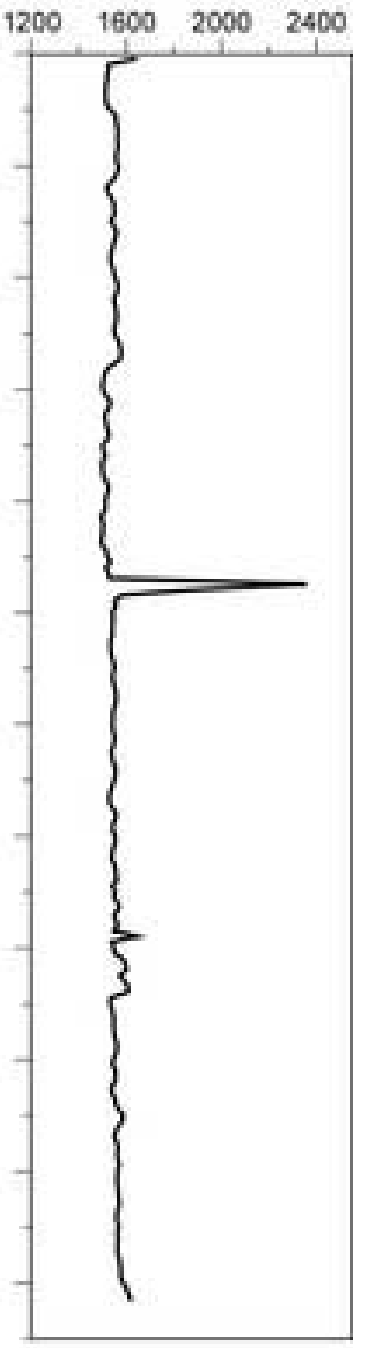

(e) 
igure 8

Click here to download high resolution image

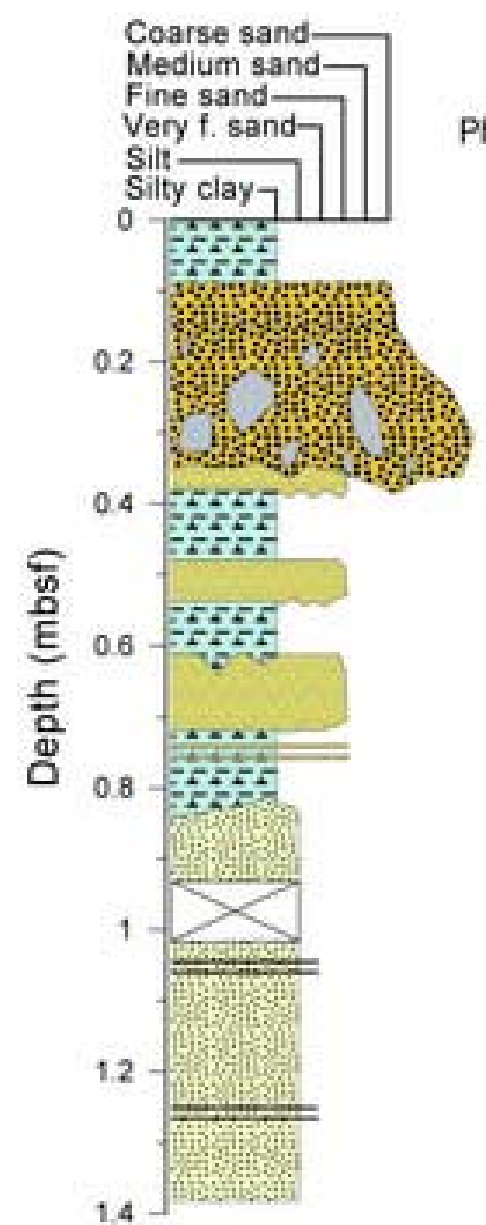

(a)
Photography

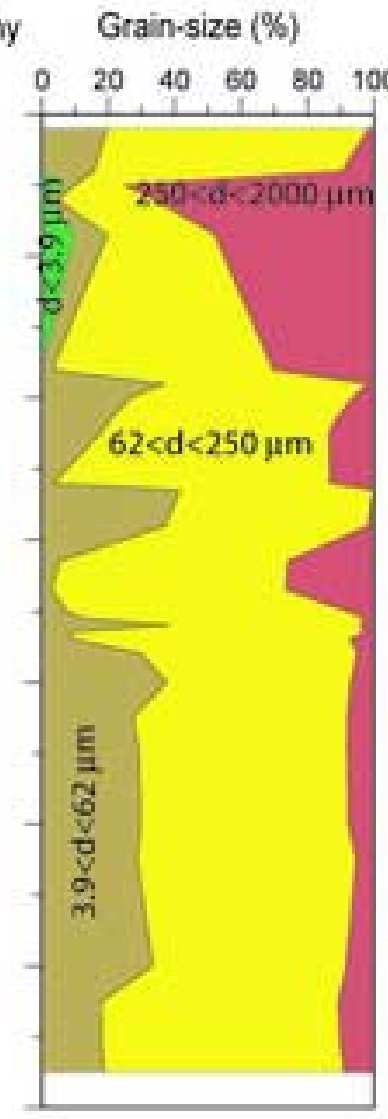

(c)

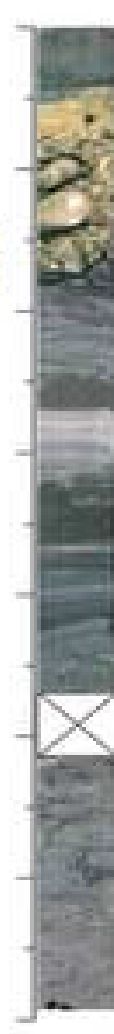

(b)

$\gamma\left(\mathrm{kN} / \mathrm{m}^{3}\right)$

$V_{\rho}(\mathrm{m} / \mathrm{s})$

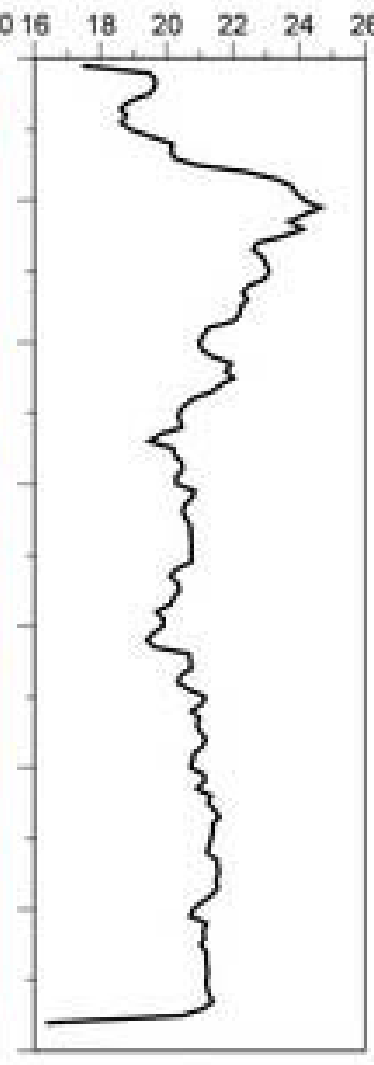

(d)

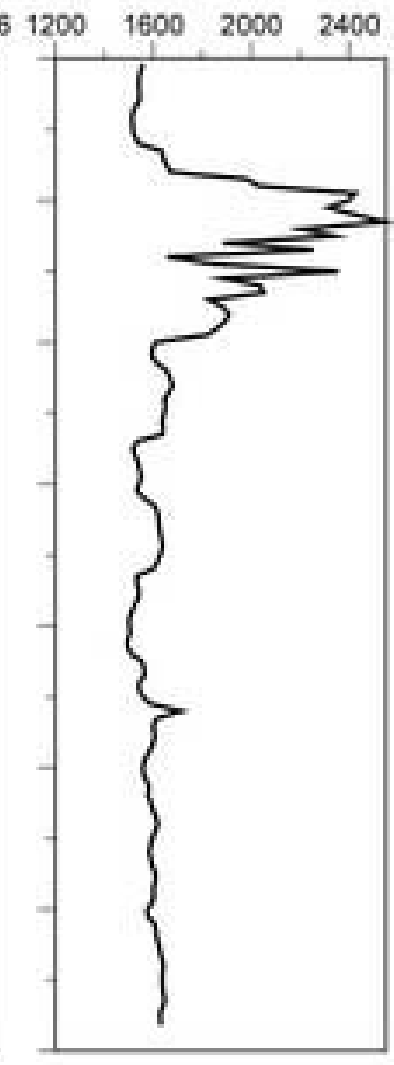

(e) 


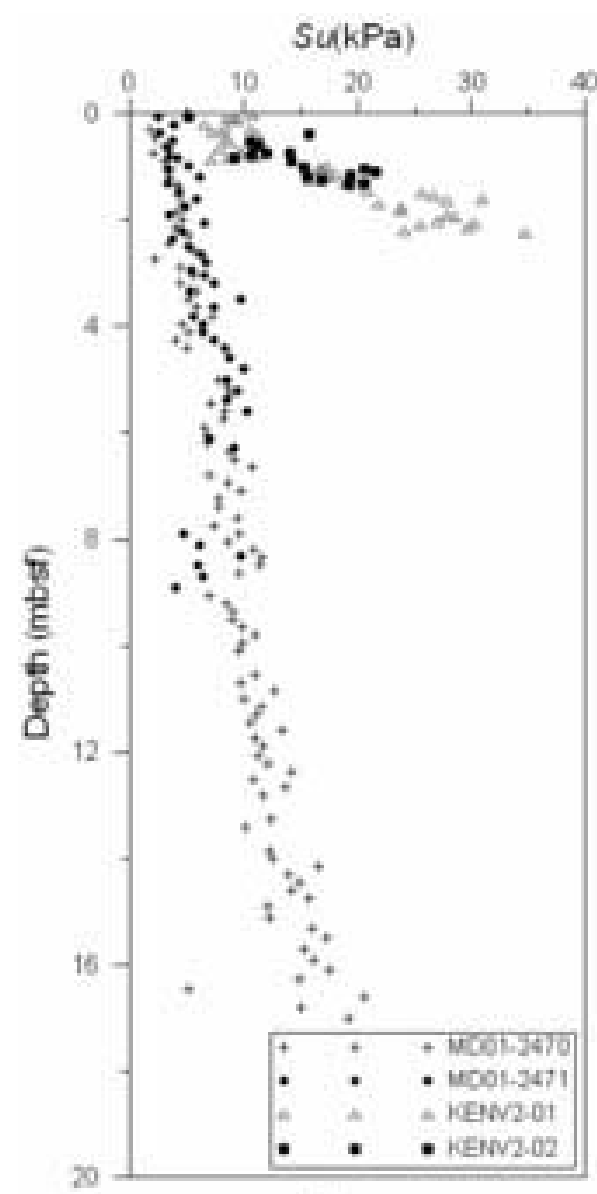

(a)

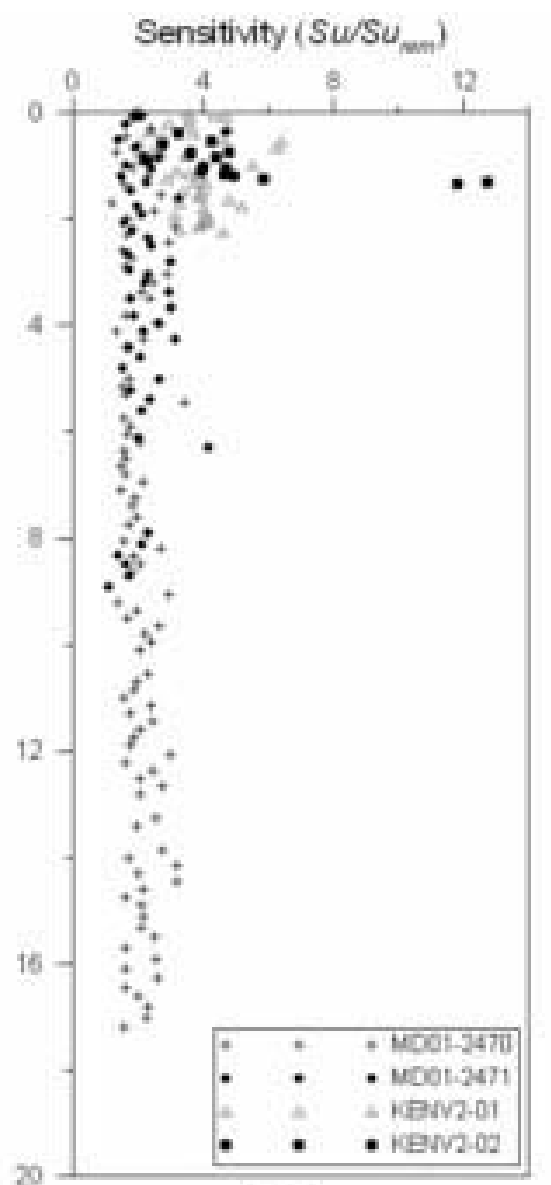

(b)

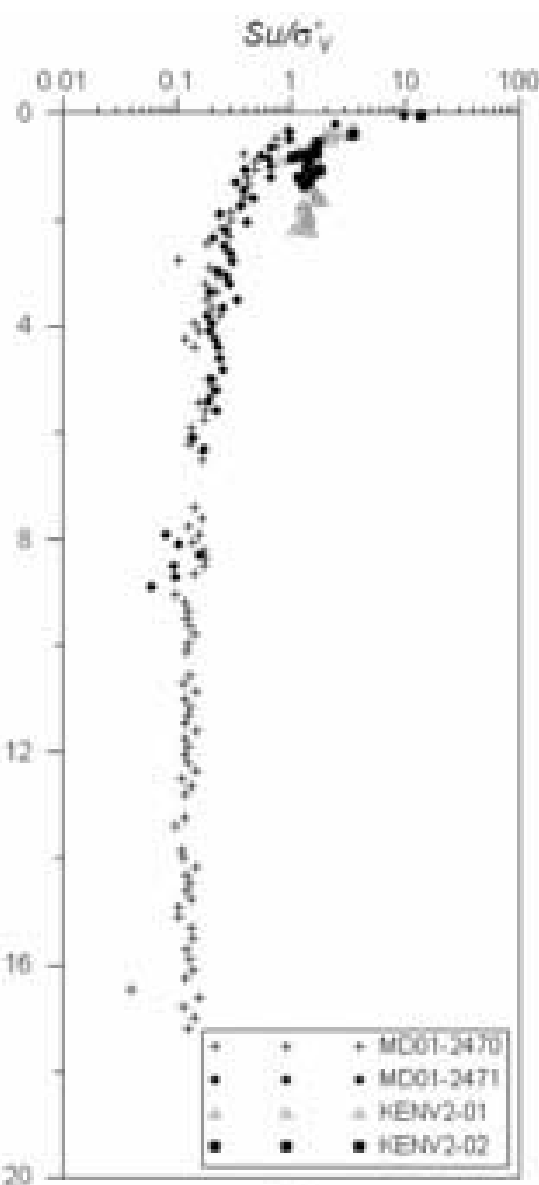

(c) 


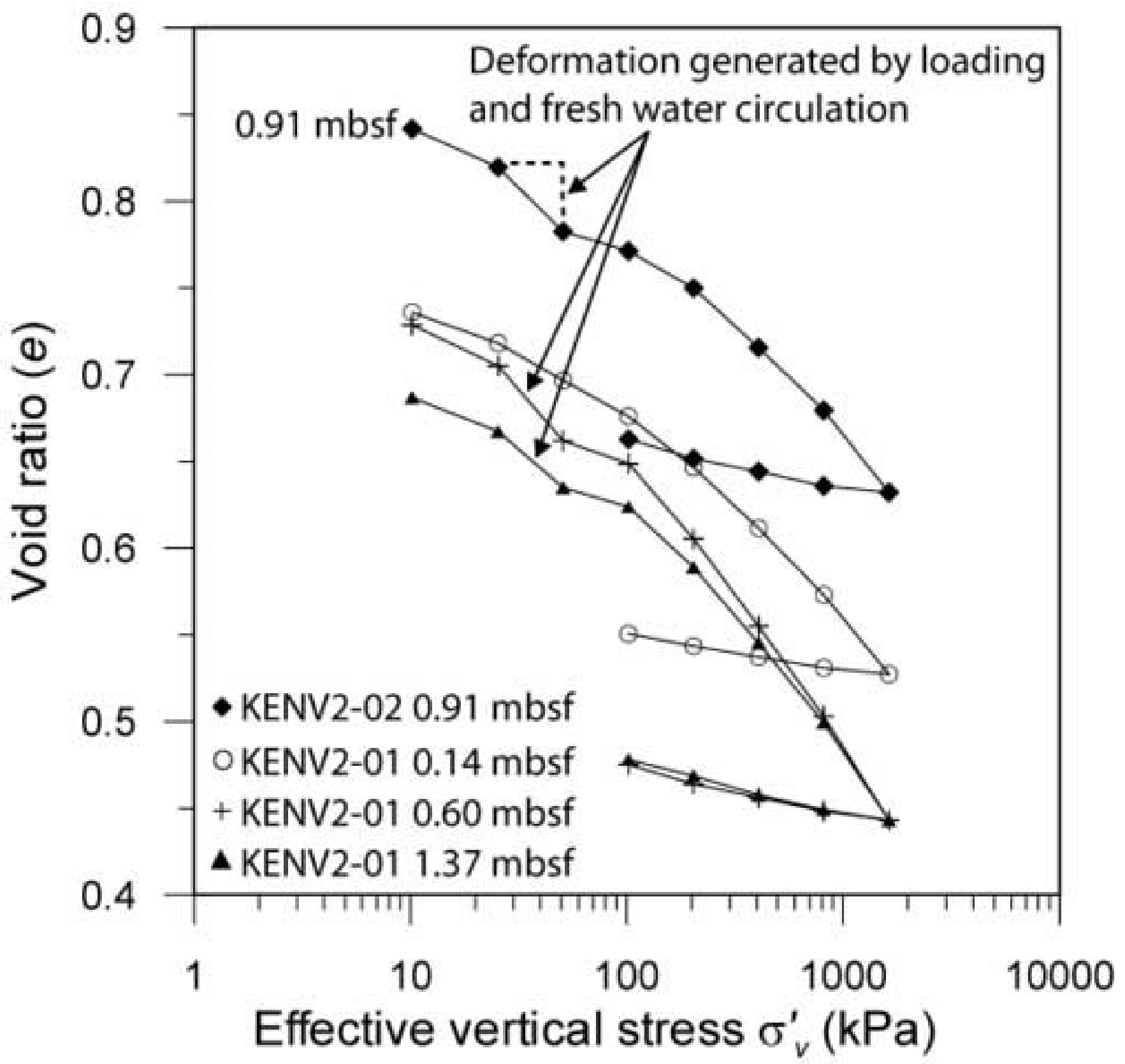


(a)

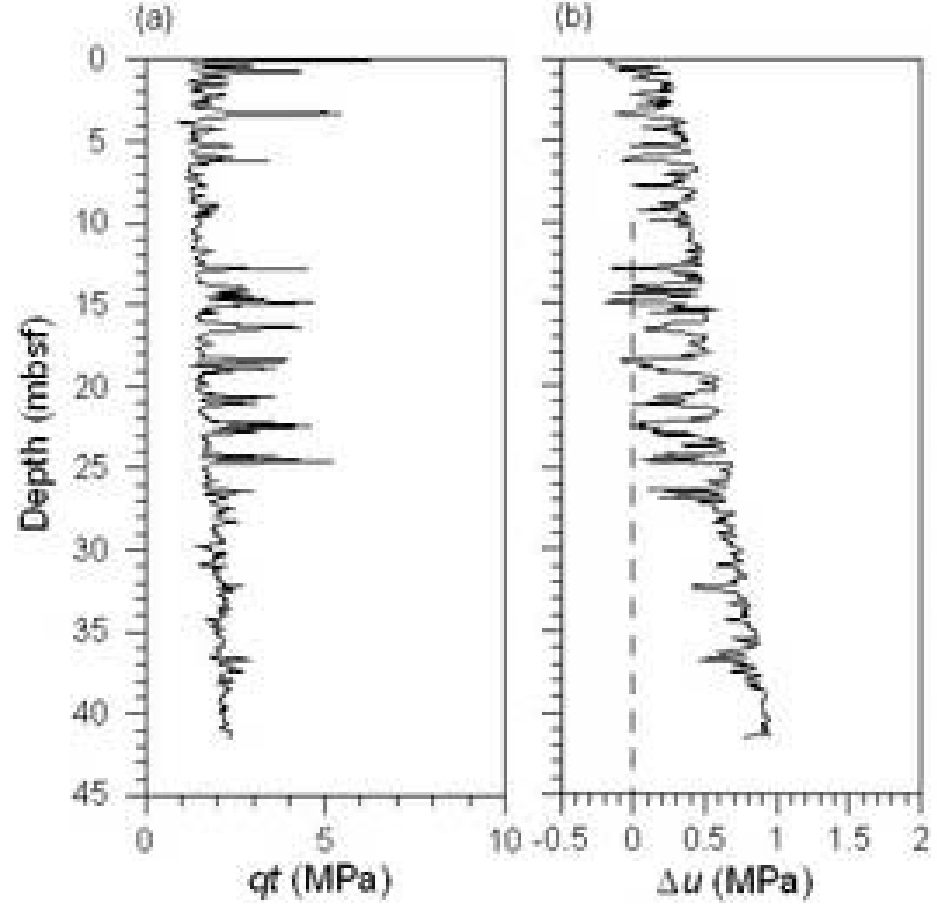

(c)

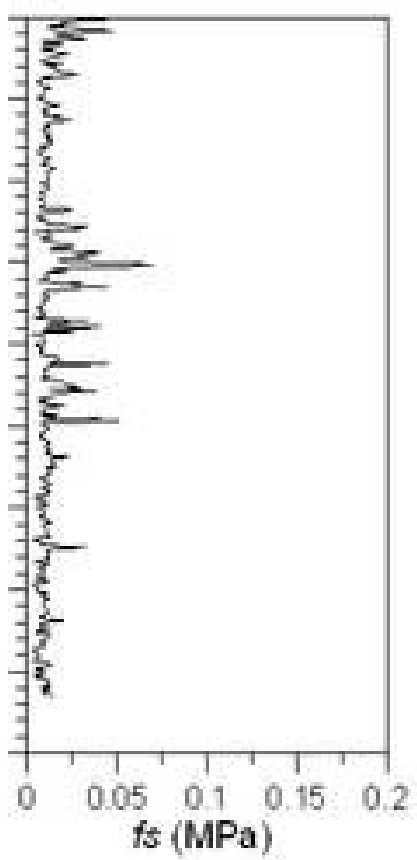

(d)

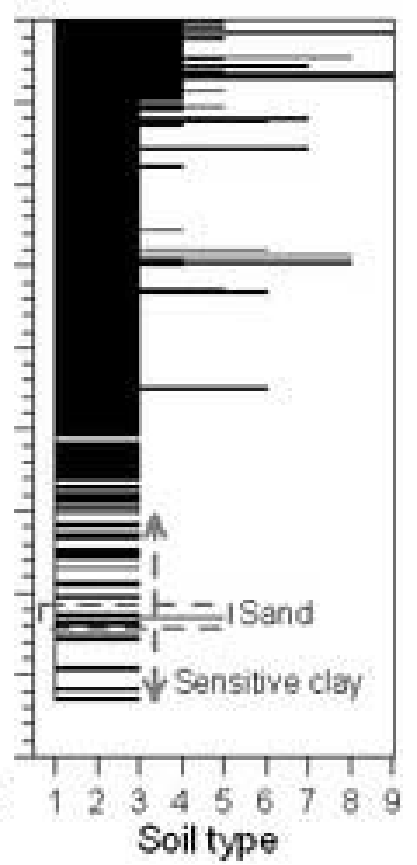


igure 12

Click here to download high resolution image

(a)

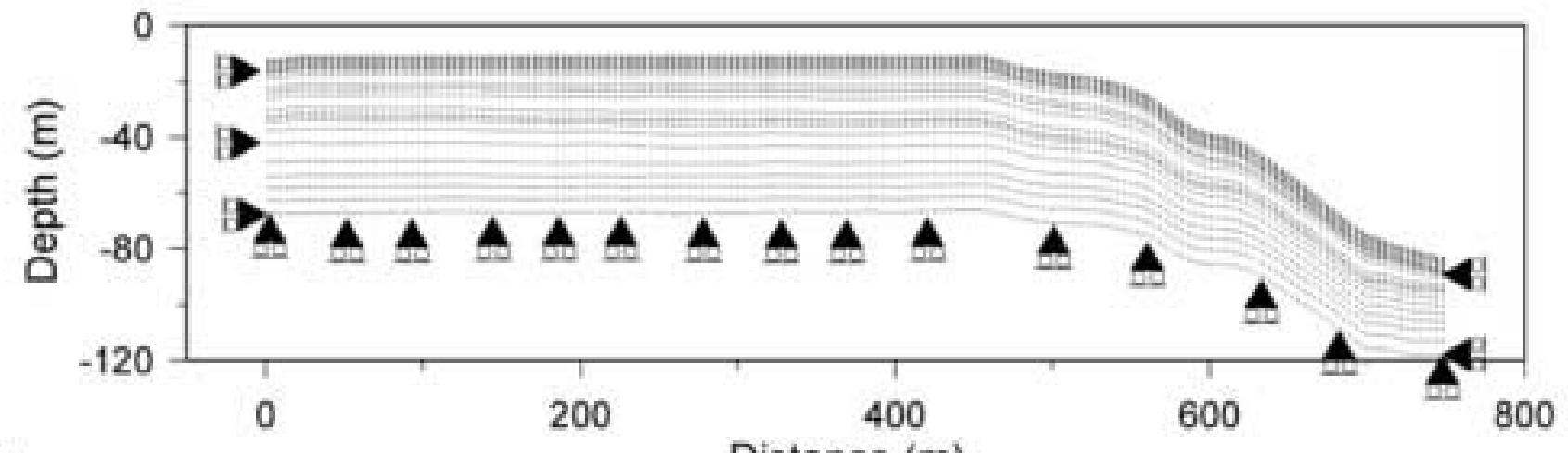

(b)

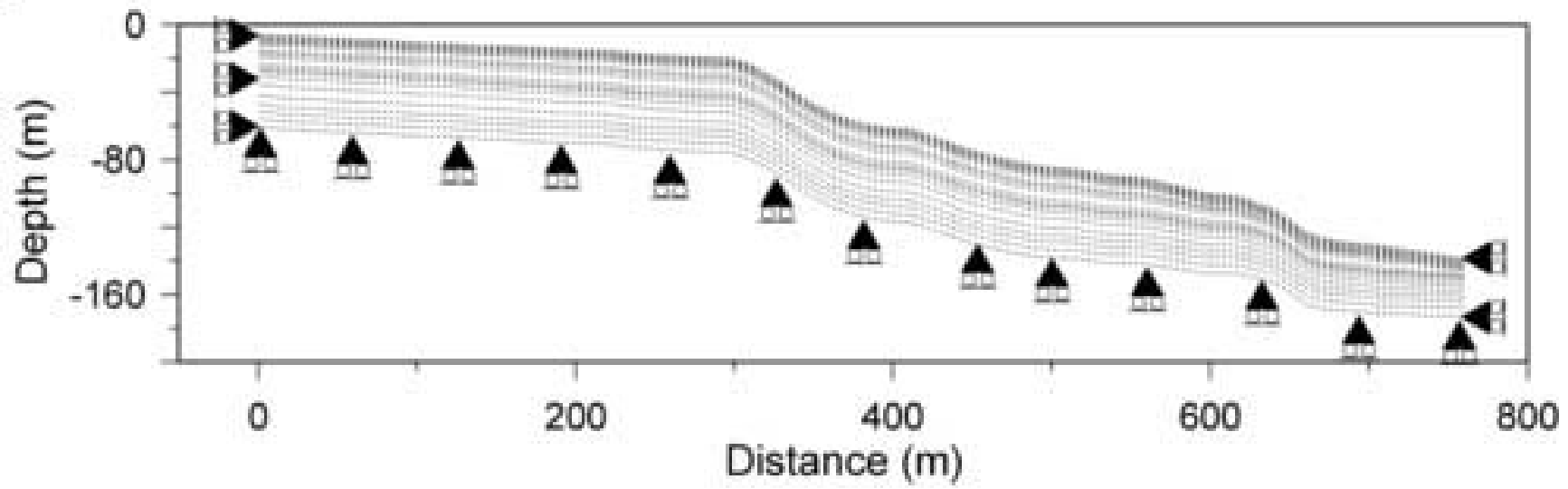


igure 13

Click here to download high resolution image

(a)

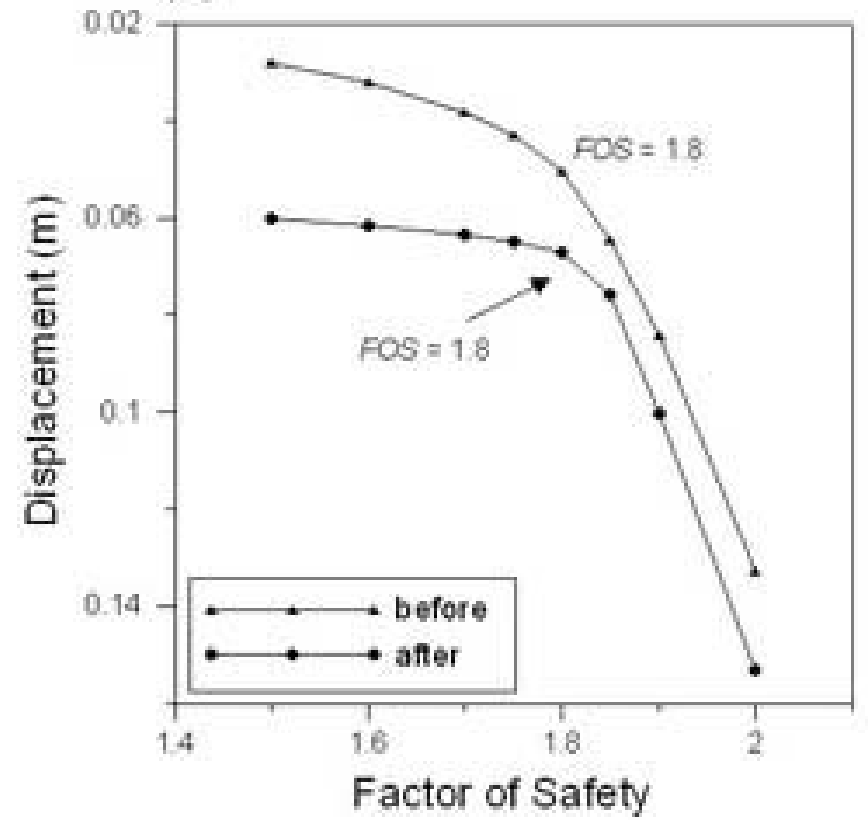

(b)

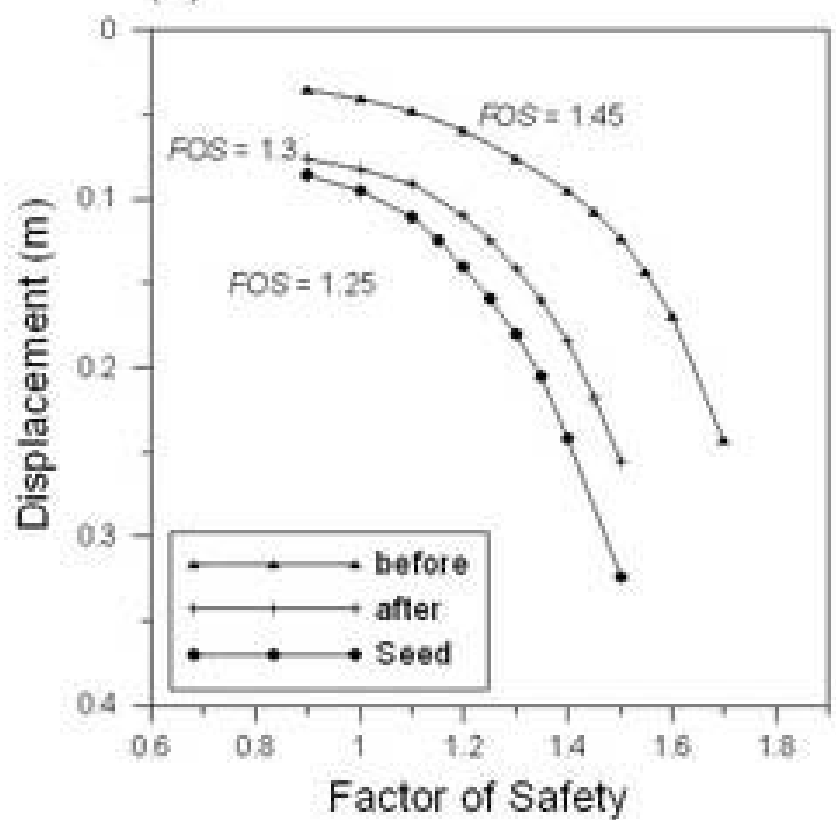


igure 14

lick here to download high resolution image

(1)

(a)

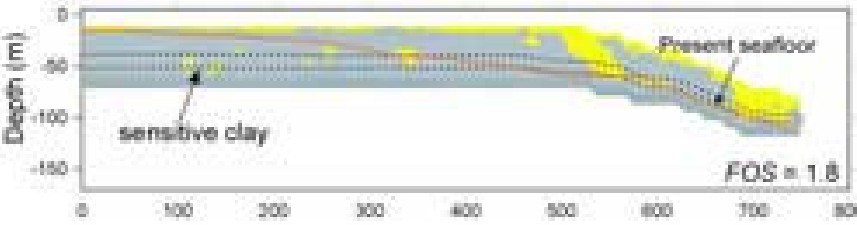

(b)

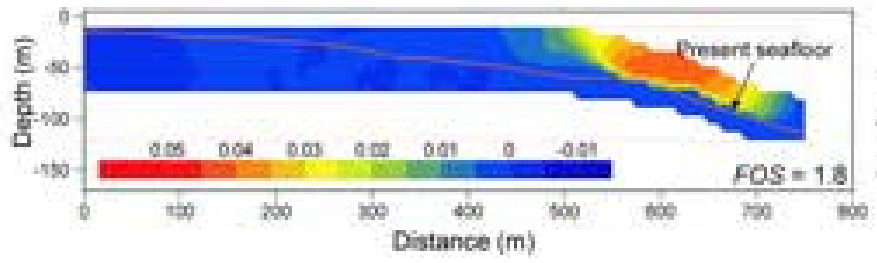

(2)
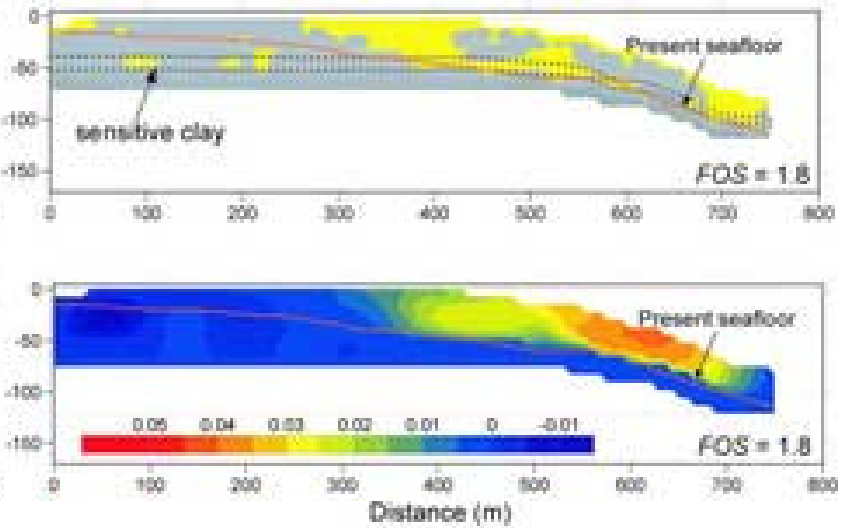
igure 15

lick here to download high resolution image

(1)

(a)

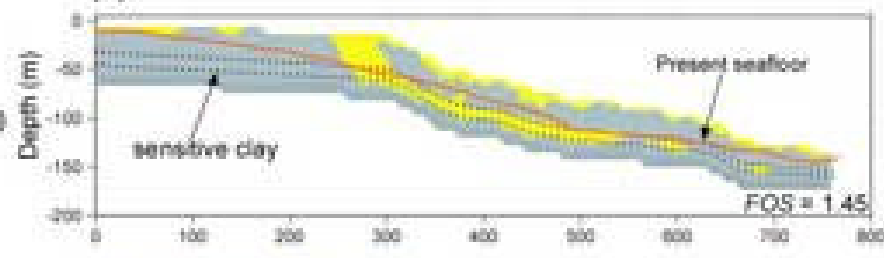

(2)

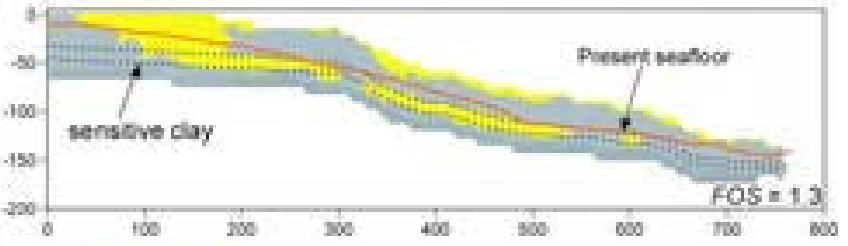

(b)
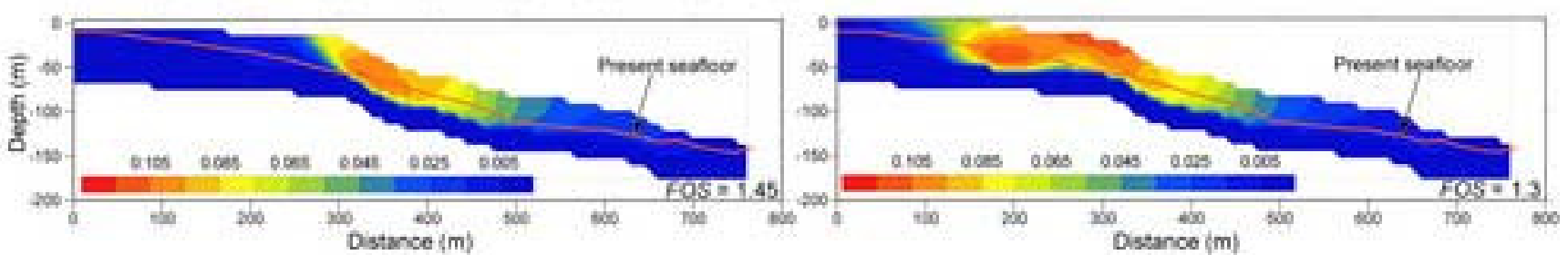
lick here to download high resolution image

(a)

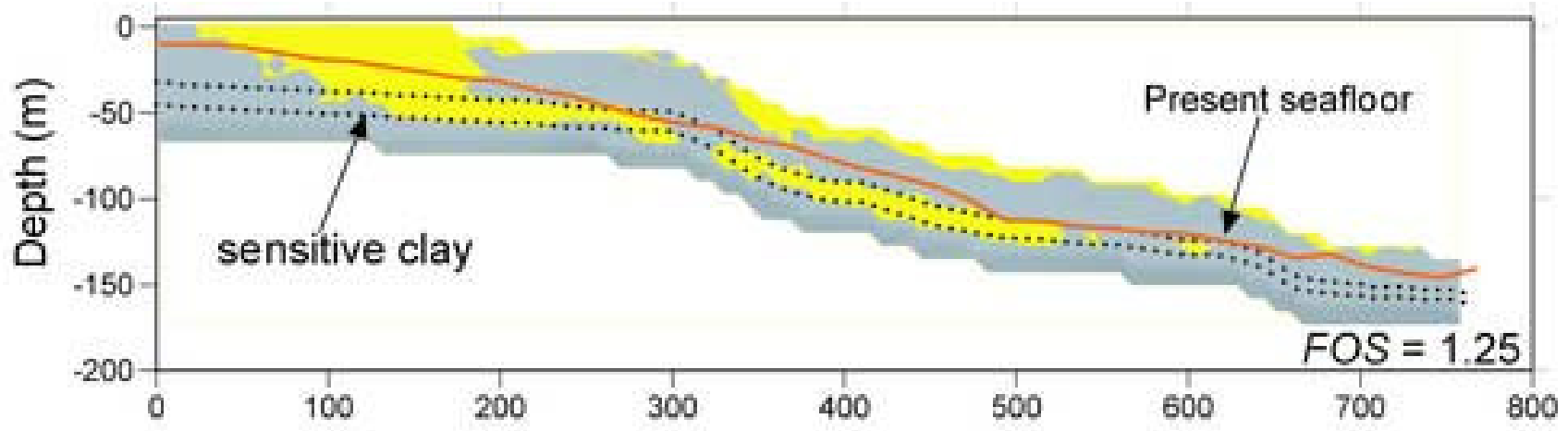

(b)

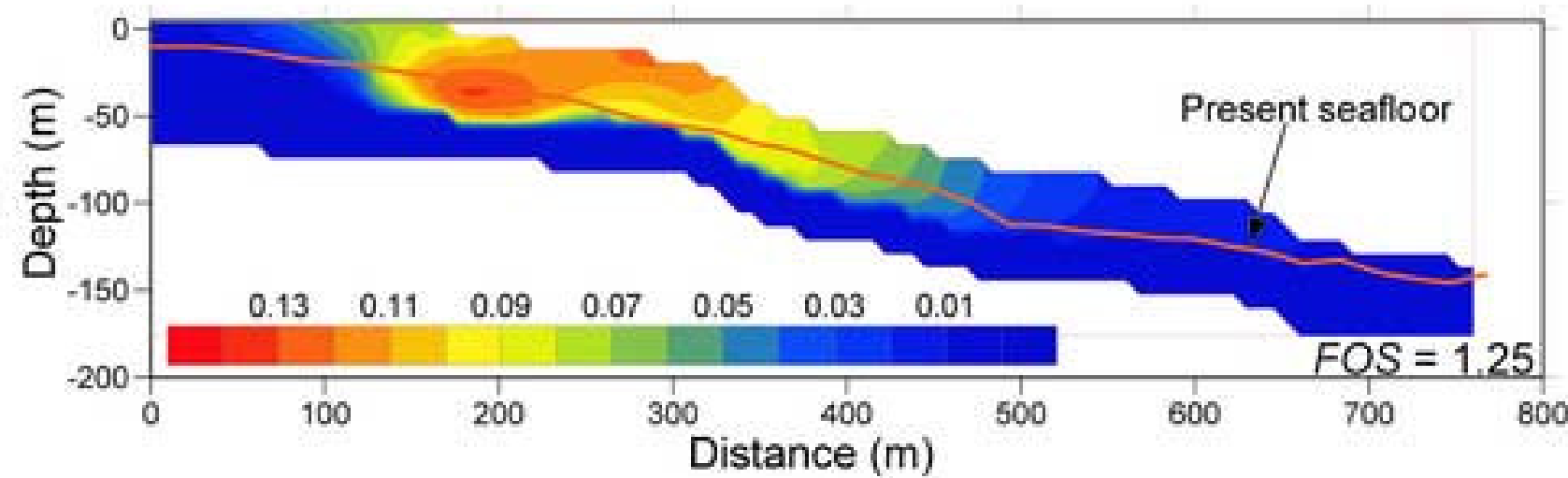


igure 17

lick here to download high resolution image

(a)

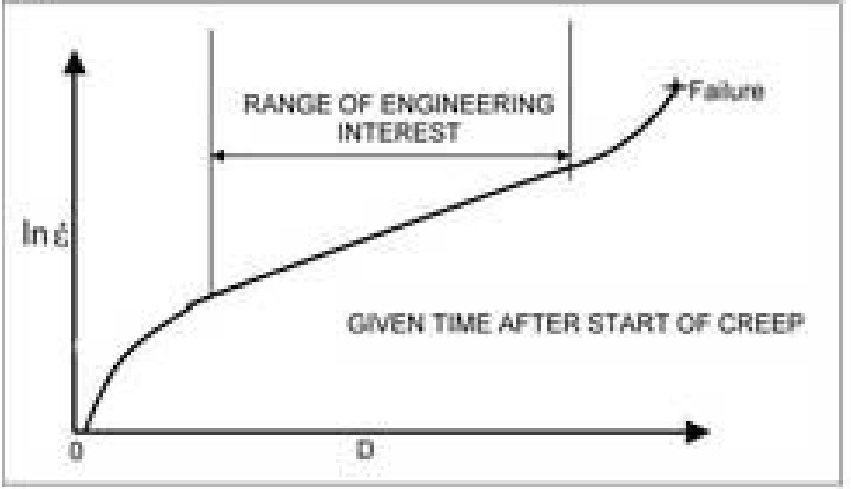

(b)

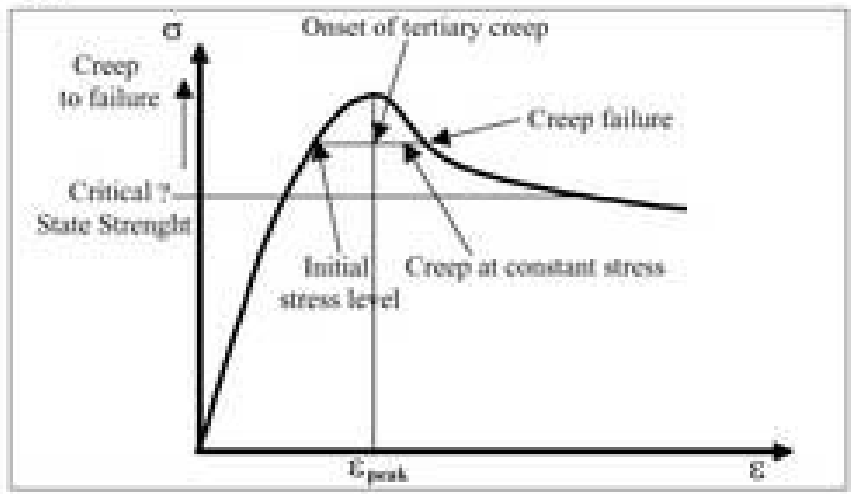


igure 18

lick here to download high resolution image

(b)

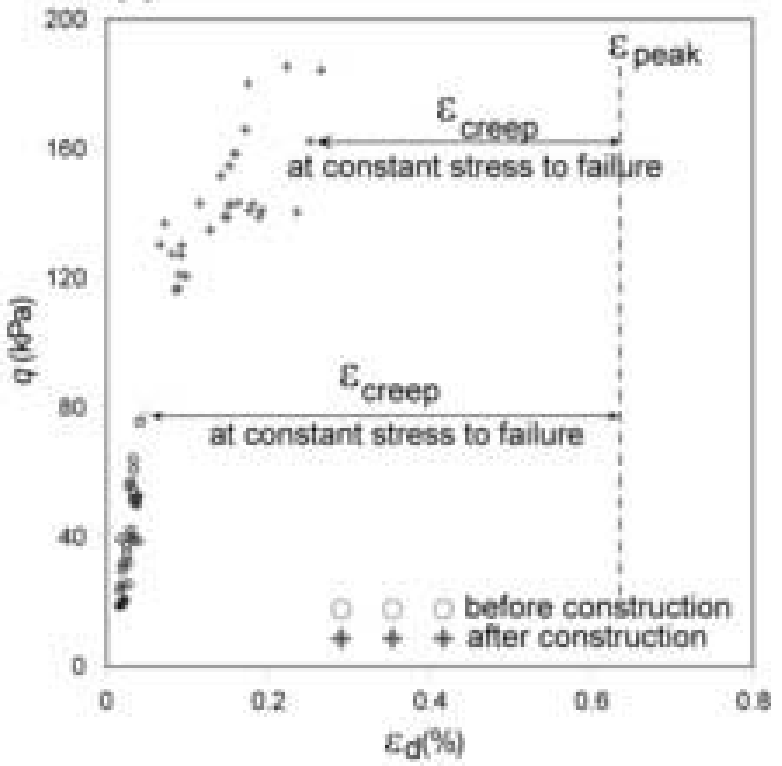

(a)

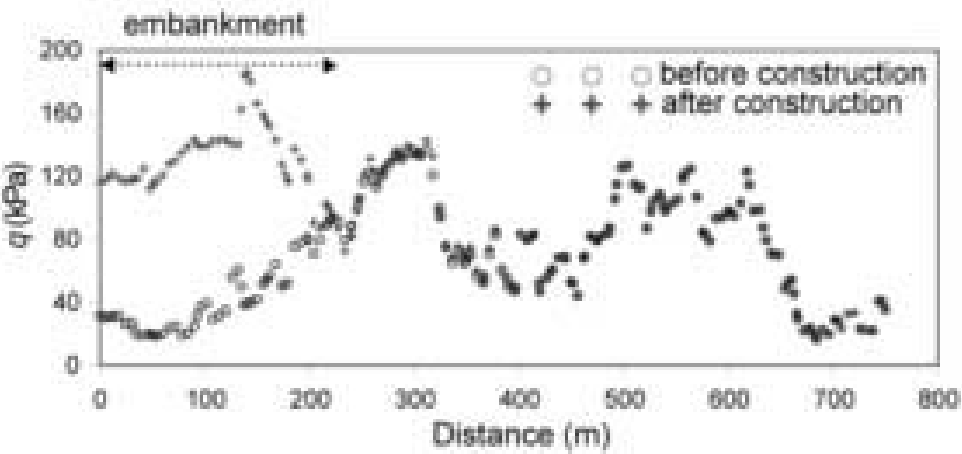


igure 19

Olick here to download high resolution image

(a)

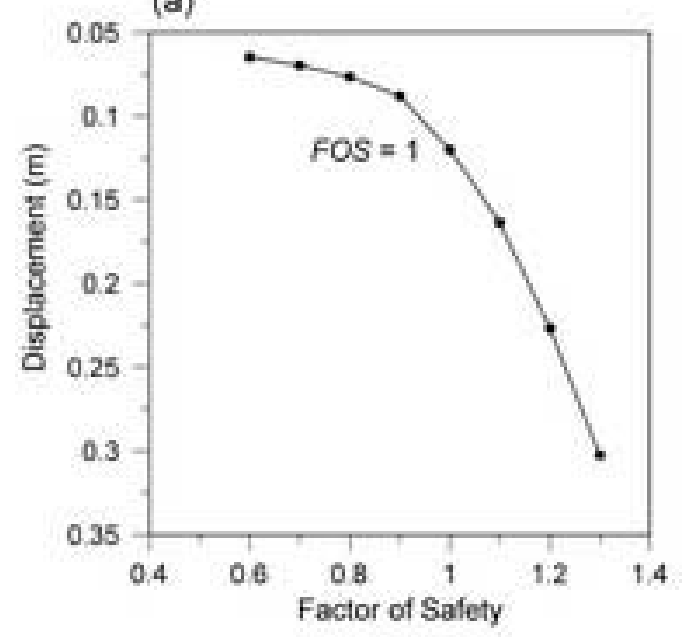

(b)
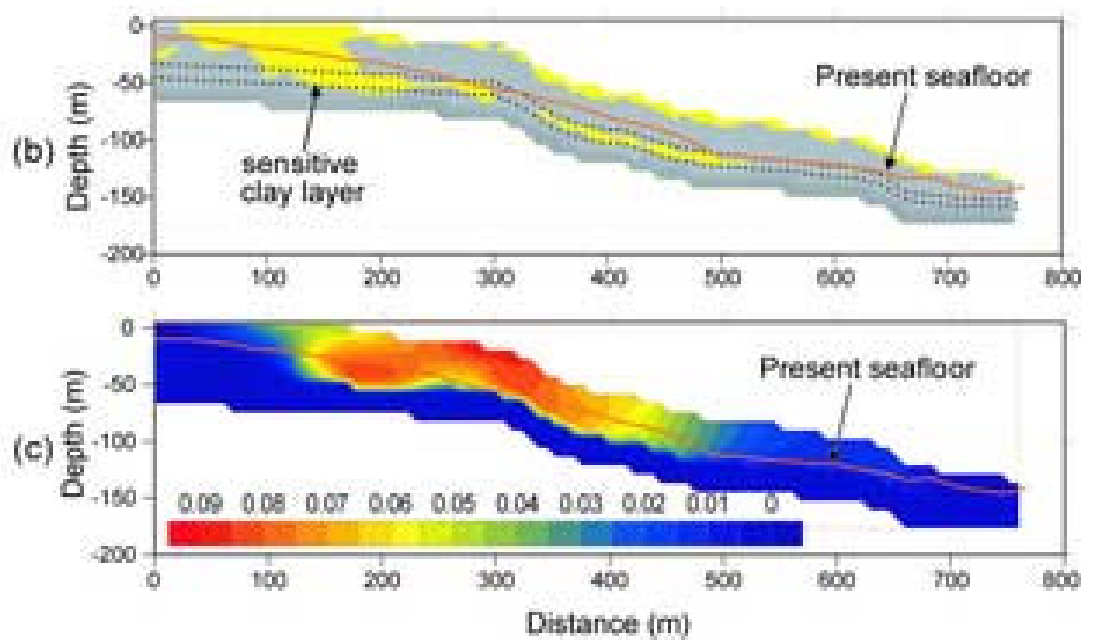

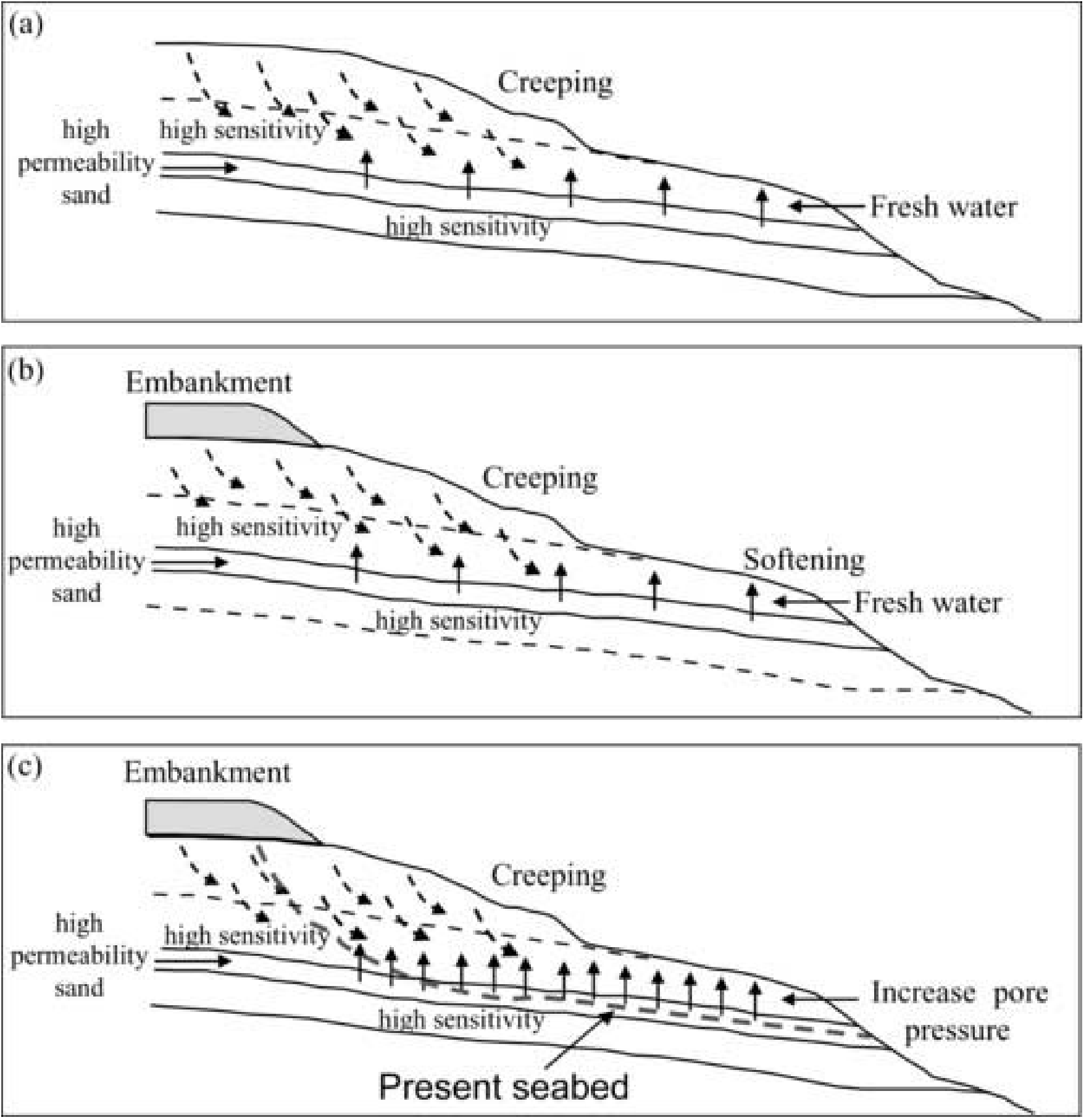
lick here to download Table: table1_MARG03239.doc

\begin{tabular}{|c|c|c|c|c|}
\hline Core & Depth (m) & $\boldsymbol{\sigma}^{\prime} \mathbf{p ~ ( k P a )}$ & $\boldsymbol{\sigma}^{\prime} \mathbf{v}(\mathbf{k P a})$ & OCR \\
\hline KENV2-01 & 0,14 & 70,6 & 1,27 & 55,6 \\
\hline KENV2-01 & 0,6 & 116,2 & 6,02 & 19,3 \\
\hline KENV2-01 & 1,37 & 155,6 & 13,88 & 11,21 \\
\hline KENV2-02 & 0,91 & 210 & 9,92 & 21,17 \\
\hline
\end{tabular}

TABLE 1 


\begin{tabular}{|c|c|cc|cc|}
\hline Layer & $\begin{array}{c}\text { Lithology } \\
\text { (from PZ11) }\end{array}$ & $\begin{array}{c}\text { Thickness (m) } \\
(\text { from PZ11) }\end{array}$ & $\begin{array}{c}\text { Su }(\mathrm{kPa}) \\
\text { (from PZ11) }\end{array}$ & $\begin{array}{c}\varphi(\text { degrees }) \\
(\text { from PZ11) }\end{array}$ & $\begin{array}{c}\gamma^{\prime}\left(\mathrm{KN} / \mathrm{m}^{3}\right) \\
(\text { from PZ11) }\end{array}$ \\
\hline $\mathbf{1}$ & Sand & 0,05 & 0 & 34 & 6,5 \\
\hline $\mathbf{2}$ & Clay & 0,95 & 67,28 & 0 & 6,5 \\
\hline $\mathbf{3}$ & Silt & 1,35 & 0 & 36,9 & 6,5 \\
\hline $\mathbf{4}$ & Clay & 1,75 & 61,89 & 0 & 6,5 \\
\hline $\mathbf{5}$ & Clay & 0,7 & 59,2 & 0 & 5,2 \\
\hline $\mathbf{6}$ & Sand & 0,3 & 0 & 32 & 5,2 \\
\hline $\mathbf{7}$ & Clay & 6,36 & 71,78 & 0 & 5,2 \\
\hline $\mathbf{8}$ & Sand & 0,4 & 0 & 33 & 5,2 \\
\hline $\mathbf{9}$ & Silty clay & 8,53 & 70,39 & 0 & 7,15 \\
\hline $\mathbf{1 0}$ & Sand & 0,5 & 0 & 33 & 7,8 \\
\hline $\mathbf{1 1}$ & Silty clay & 5,9 & 65,26 & 0 & 7,93 \\
\hline $\mathbf{1 2}$ & Sensitive clay & 12,9 & 68,62 & 0 & 9,1 \\
\hline $\mathbf{1 3}$ & Subs tratum & 8,35 & 130 & 0 & 10,4 \\
$\mathbf{1 4}$ & Subs tratum & 9,45 & 400 & 0 & 10,7 \\
\hline
\end{tabular}

Su: Undrained shear strength $\varphi$ : Internal friction angle

$\gamma$ ': Submerged unit weight

\section{TABLE 2}


flick here to download Table: table3_MARGO3239.doc

\begin{tabular}{|l|c|c|c|c|cc|}
\cline { 2 - 6 } \multicolumn{1}{c|}{} & \multicolumn{4}{c|}{ NW-SE Profile } & \multicolumn{2}{c|}{ ENE-WS W Profile } \\
\cline { 2 - 7 } \multicolumn{1}{c|}{} & $\begin{array}{c}\text { Before } \\
\text { construction }\end{array}$ & $\begin{array}{c}\text { After } \\
\text { construction }\end{array}$ & $\begin{array}{c}\text { Seed's } \\
\text { hypothesis }\end{array}$ & $\begin{array}{c}\text { Sensitive } \\
\text { clay creep }\end{array}$ & $\begin{array}{c}\text { Before } \\
\text { construction }\end{array}$ & $\begin{array}{c}\text { After } \\
\text { construction }\end{array}$ \\
\hline FOS & 1.45 & 1.3 & 1.25 & 1 & 1.8 & 1.8 \\
\hline
\end{tabular}

\section{TABLE 3}

